\title{
ADICIONES AL CONOCIMIENTO DE LOS HONGOS POLIPOROIDES DE CHIAPAS
}

\author{
Nora B. Medina-Jaritz ${ }^{1,3}$, Mauricio R. Palacios-Pacheco ${ }^{2}$ Y \\ RicARdo VALENZUELA-GARZA ${ }^{2}$ \\ ${ }^{1}$ Instituto Politécnico Nacional, Escuela Nacional de Ciencias Biológicas, \\ Departamento de Botánica, Laboratorio de Fisiología Vegetal, \\ Prolongación de Carpio esquina Plan de Ayala s/n, \\ Casco de Sto. Tomás, 11340 México, D.F., México. \\ ${ }^{2}$ Instituto Politécnico Nacional, Escuela Nacional de Ciencias Biológicas, \\ Departamento de Botánica, Laboratorio de Micología, \\ Prolongación de Carpio esquina Plan de Ayala s/n, \\ Casco de Sto. Tomás, 11340 México, D.F., México. \\ ${ }^{3}$ Autor para la correspondencia: noramedinaj@gmail.com
}

\section{RESUMEN}

Se registran 24 especies de poliporoides incluidas en 14 géneros pertenecientes a cinco familias. Este estudio está basado en 93 ejemplares recolectados en el bosque tropical de los alrededores de la zona arqueológica de Yaxchilán, Chiapas. Se realizaron descripciones de cada una de las especies tomando en cuenta características macro y microscópicas, de acuerdo con los lineamientos que dicta la taxonomía moderna.

Palabras clave: Chiapas, México, Polyporales, taxonomía.

\section{ABSTRACT}

We report 24 polypore species belonging to five families. This study is based on 93 specimens collected in the rain forest that surrounds the archeological zone of Yaxchilán, Chiapas. We made descriptions in accordance with the guidelines of modern taxonomy.

Key words: Chiapas, Mexico, Polyporales, taxonomy. 


\section{INTRODUCCIÓN}

Los hongos poliporoides se distinguen porque sus basidiomas exhiben un himenóforo con poros circulares, irpiciformes, labirintiformes o laminares; de consistencia subcarnosa a leñosa; pueden ser anuales, bienales o perennes; resupinados, sésiles, efuso-reflejados o pileados a estipitados y de hábito solitario o gregario (Ryvarden, 1991). Son principalmente degradadores de madera, por lo que contribuyen al reciclaje de los elementos biogeoquímicos (Cooke y Rayner, 1984), además de que muchos de ellos pueden parasitar un gran número de especies arbóreas en los diversos tipos de vegetación. Se reconocen dos tipos de pudrición en la madera causados por estos organismos: la morena y la blanca. En el primer caso, las enzimas del hongo únicamente degradan a la celulosa de la planta, por lo que la zona afectada adquiere un color café debido a la presencia de lignina no degradada. La pudrición blanca se observa cuando el hongo se nutre tanto de la celulosa como de la lignina, por lo que además de presentar la decoloración característica, disminuye el peso del sustrato ya que éste se degrada totalmente por la acción de las celulasa y ligninaperoxidasa (Cullen y Kersten, 1996).

Se han realizado diversos trabajos acerca de los poliporoides de la región sureste del país, además de que en numerosos estudios se han citado especies de este grupo provenientes de Chiapas, entre ellos tenemos los de Guzmán (1963, 1972, 1977), Guzmán y Johnson (1974), Chacón y Guzmán (1984), Pérez-Moreno y Villarreal (1988), Chanona-Gómez et al. (2007). Por otro lado, existen las revisiones bibliográficas de Guzmán y Herrera (1972) y de Bandala et al. (1993).

La zona arqueológica de Yaxchilán se encuentra en la provincia fisiográfica de la República Mexicana conocida como Planicie Costera o como Planicie Costera Sur Oriental (Rzedowski, 1978), en la región noreste del estado de Chiapas y noreste del municipio de Ocosingo; entre las coordenadas $16^{\circ} 52^{\prime} 40^{\prime \prime}$ y $16^{\circ} 54^{\prime} 25^{\prime \prime}$ de latitud norte y $90^{\circ} 57^{\prime} 30^{\prime \prime}$ y $90^{\circ} 58^{\prime} 45^{\prime \prime}$ de longitud oeste, a una altitud de $150 \mathrm{~m}$. Se localiza a $136 \mathrm{~km}$ del poblado de Ocosingo, y está rodeada por el río Usumacinta en todos los puntos cardinales, excepto al sureste. El clima es cálido-húmedo con lluvias todo el año (Am), su temperatura mínima extrema es de $0{ }^{\circ} \mathrm{C}$ y su precipitación media anual es de aproximadamente $1600 \mathrm{~mm}$ (Anónimo, 1981). El tipo de vegetación de la zona de estudio es bosque tropical perennifolio, con especies tales como a Guarea excelsa Kunth, Guatteria anomala R. E. Fries, Pithecellobium arboreum (L.) Urban, Quararibea funebris (Llave) Vischer, Swietenia macrophylla King, Terminalia amazonia (J. F. Gmelin) Exell y Vatairea lundellii (Standley) Killip ex Record, según Rzedowski (1978) y Breedlove (1981). 


\section{MATERIAL Y MÉTODOS}

Durante la realización de este trabajo se revisó la colección del Herbario Micológico de la Escuela Nacional de Ciencias Biológicas (ENCB) y se llevó a cabo una exploración en la zona de estudio, recolectándose un total de 101 especímenes durante el periodo comprendido entre el 29 de marzo y el 2 de abril de 1986. El material fue obtenido utilizando las técnicas usuales en micología (Cifuentes et al., 1986; Gilbertson y Ryvarden, 1986), para lo cual se precisó llevar canasta, cuchillo de campo, bolsas y segmentos de papel encerado, lápiz y libreta. Al momento de la recolección se tomaron los datos de sustrato u hospedero, pudrición de la madera (blanca, morena o ausente) y reacciones al tacto. Posteriormente, con los hongos aún frescos, se tomaron los datos de tamaño, textura, consistencia, color y reacciones macroquímicas con $\mathrm{KOH}$ a $5 \%$, todo ello en las diferentes partes del basidioma (píleo, contexto, himenóforo y estípite). Para tomar los datos referentes al color se utilizó la guía de Kornerup y Wanscher (1978), llevando a cabo la comparación de colores a la luz del día. Después se procedió a secar los ejemplares con una estufa de asbesto calentada al sol y con una estufa eléctrica durante el tiempo necesario según el tamaño, consistencia y humedad de los mismos; más tarde fueron sometidos a técnicas rutinarias de herborizado en laboratorio. El material así tratado se describió microscópicamente, para lo cual se observaron preparaciones de macerados o cortes longitudinales y transversales de las diferentes partes del basidioma, en las cuales se determinó el sistema hifal, la presencia o ausencia de fíbulas, cistidios, cistidiolos, setas, basidios y esporas; así como las características de estas estructuras: tamaño, forma, color, grosor de las paredes, ornamentación y reacciones macroquímicas en $\mathrm{KOH}$ a $5 \%$. En los casos que así lo requerían, se emplearon colorantes como floxina a $1 \%$ o rojo Congo a $1 \%$, para favorecer la observación de las estructuras antes mencionadas. Se dibujaron esquemas a través de una cámara clara y se anexó la escala gráfica correspondiente. Posteriormente se determinaron taxonómicamente mediante el empleo de claves y literatura especializada (Overholts, 1953; Bondartsev, 1971; Domanski, 1972; Domanski et al., 1973; Gilbertson, 1976; Ryvarden y Johansen, 1980; Gilbertson y Ryvarden, 1986 y 1987 y Ryvarden y Gilbertson, 1993 a y b). Se recurrió a la página de index fungorum (www.indexfungorum.org) para verificar la nomenclatura y ubicación taxonómica de cada especie. En las descripciones se presenta la información sobre la distribución conocida en México, la cual se obtuvo mediante la consulta bibliográfica (Bandala et al., 1993). El material estudiado se depositó en el herbario de la Escuela Nacional de Ciencias Biológicas del Instituto Politécnico Nacional (ENCB-IPN); 
las descripciones se elaboraron a partir de ese material y, en algunos casos, de ejemplares recolectados en otras ocasiones (anotando entonces las fechas). Finalmente, se proporciona el número de la base de datos CONABIO de los ejemplares incluidos en el proyecto "Las familias Polyporaceae sensu stricto y Albatrellaceae en México" (clave H201).

\section{RESULTADOS}

Se encontraron y describieron un total de 24 especies de poliporáceos incluidas en 15 géneros pertenecientes a cinco familias, de las cuales la mejor representada es Polyporaceae con 16 especies, enseguida Meripilaceae con tres, posteriormente las familias Hymenochaetaceae y Fomitopsidaceae con dos cada una y, finalmente, Meruliaceae, con una sola (Cuadro 1) las cuales se describen a continuación.

Familia Fomitopsidaceae

Fomitopsis cupreorosea (Berk.) J. Carranza \& Gilb., Mycotaxon 25(2): 476 (1986). Figs. 1-4.

Basidioma anual, pileado-sésil, dimidiado, aplanado, de consistencia corchosa, de 17-100 X 17-65 X 13-18 mm. Píleo aterciopelado, zonado, rojo pálido a café-anaranjado (7A3, 7B4, 7C5) en ejemplares jóvenes, y con tonos café-anaranjados pálidos y cafés claros $(7 \mathrm{C} 3,7 \mathrm{D} 4)$ en ejemplares viejos; margen ondulado, agudo y estéril. Himenóforo con poros de color rojo opaco a rojo-grisáceo (9C4, 9C5), grandes, 2-3 por $\mathrm{mm}$, angulares, irregulares a labirintiformes, con bordes delgados y ligeramente crenados; tubos rojos pálidos a rojos opacos (9A3, 9B3), de 1-10 mm de longitud, no estratificados. Contexto concolor con los tubos, de $0.5-15 \mathrm{~mm}$ de grosor, fibroso, simple; con sabor ácido, olor no detectado. Sistema hifal trimítico; hifas generativas de 1.2-2 $\mu \mathrm{m}$ de diámetro, con fíbulas, hialinas, con paredes delgadas, ramificadas o no; hifas esqueléticas de 3.2-4.8 $\mu \mathrm{m}$ de diámetro, hialinas a cafés claras, con paredes gruesas a casi sólidas, rectas a sinuosas; hifas conectivas de 1.6-2.4 $\mu \mathrm{m}$ de diámetro, hialinas, con paredes gruesas a sólidas, sinuosas. Cistidios y otros elementos himeniales estériles ausentes. Basidios no observados. Basidiosporas de 4-6.4 X 2-3.2 $\mu \mathrm{m}$, elipsoides a cilíndricas, hialinas, inamiloides, con pared delgada, lisas.

Reacciones macroquímicas: cambia temporalmente a negro-púrpura en todas sus partes. 
Cuadro 1. Lista de especies registradas en Yaxchilán.

\begin{tabular}{|c|c|c|}
\hline Familia & Género & Especie \\
\hline Fomitopsidaceae & Fomitopsis & $\begin{array}{l}\text { F. cupreorosea (Berk.) J. Carranza \& Gilb. } \\
\text { F. feei (Fr.) Kreisel }\end{array}$ \\
\hline \multirow[t]{2}{*}{ Hymenochaetaceae } & Fuscoporia & $\begin{array}{l}\text { F. callimorpha (Lév.) Groposo, Log.-Leite \& } \\
\text { Góes-Neto }\end{array}$ \\
\hline & Phylloporia & P. pectinata (Klotzsch) Ryvarden \\
\hline \multirow[t]{3}{*}{ Meripilaceae } & Hydnopolyporus & H. fimbriatus (Fr.) D.A. Reid \\
\hline & Rigidoporus & R. microporus (Sw.) Overeem \\
\hline & & R. ulmarius (Sowerby) Imazeki \\
\hline Meruliaceae & Gloeoporus & G. thelephoroides (Hook.) G. Cunn. \\
\hline \multirow[t]{16}{*}{ Polyporaceae } & Coriolopsis & C. brunneoleuca (Berk.) Ryvarden \\
\hline & & C. byrsina (Mont.) Ryvarden \\
\hline & & C. caperata (Berk.) Murrill \\
\hline & & C. polyzona (Pers.) Ryvarden \\
\hline & Earliella & E. scabrosa (Pers.) Gilb. \& Ryvarden \\
\hline & Favolus & F. tenuiculus P. Beauv. \\
\hline & Fomes & F. fasciatus (Sw.) Cooke \\
\hline & Hexagonia & H. hydnoides (Sw.) M. Fidalgo \\
\hline & & H. tenuis (Hook.) Fr. \\
\hline & Lenzites & L. elegans (Spreng.) Pat. \\
\hline & Loweporus & L. tephroporus (Mont.) Ryvarden \\
\hline & Polyporus & P. leprieurii Mont. \\
\hline & & P. tricholoma Mont. \\
\hline & & P. varius (Pers.) Fr. \\
\hline & Trametes & T. maxima (Mont.) A. David \& Rajch. \\
\hline & & T. villosa (Sw.) Kreisel \\
\hline
\end{tabular}

Hábitat: Sobre madera muerta de angiospermas. Ocasiona pudrición morena. Material revisado: CHIAPAS: Medina 149, Valenzuela 5034 (CONABIO 1334, 1664).

Distribución conocida en México: Oaxaca, Tabasco y Veracruz (Bandala et al., 1993; Raymundo y Valenzuela, 2003).

Fomitopsis feei (Fr.) Kreisel, Ciencias Biológicas, Cuba 16: 83 (1971). Figs. 5-8. 
Basidioma anual, pileado-sésil, ocasionalmente con una constricción a manera de estípite, dimidiado, gregario, de consistencia correosa a corchosa, de 25-90 X 20-65 X 5-10 mm Píleo zonado, glabro, ligeramente surcado, anaranjado brillante a anaranjado grisáceo (5A4, 5A5, 5B5), con manchas de color café-rojo-caoba (8E7), rojo-sangre oxidado a café-granate (9E7, 9D8); margen entero, agudo y estéril; todo el basidioma presenta un ligero tinte lila, a manera de sombra. Himenóforo con poros anaranjados pálidos a anaranjados brillantes $(5 \mathrm{~A} 3,5 \mathrm{~A} 4,6 \mathrm{~A} 3,6 \mathrm{~A} 4)$ con tonos de color rojo pastel (9A4), pequeños a medianos, 3-6 por mm, circulares a angulares, regulares, con bordes delgados y lisos a ondulados; tubos concoloros con el himenóforo, hasta de $2 \mathrm{~mm}$ de longitud, no estratificados. Contexto del mismo color que los tubos, hasta de $1 \mathrm{~mm}$ de grosor, simple, fibroso, con sabor terroso y olor ligeramente fúngico. Sistema hifal trimítico; hifas generativas de 2.4-3.2 $\mu \mathrm{m}$ de diámetro, con fíbulas, hialinas, con paredes delgadas; hifas esqueléticas de 2.4-3.6 $\mu \mathrm{m}$, amarillentas, con paredes gruesas a casi sólidas, rectas a ligeramente sinuosas; hifas conectivas de 1.6-3.2 $\mu \mathrm{m}$ de diámetro, hialinas, con paredes gruesas a sólidas, sinuosas. Cistidios y otros elementos himeniales estériles ausentes. Basidios no observados. Basidiosporas de 4.8-6.4 X 2.4 $\mu \mathrm{m}$, elipsoides, hialinas, inamiloides, lisas, con pared delgada.

Reacciones macroquímicas: en $\mathrm{KOH}$ a 5\% cambia a color café-púrpura o negro-púrpura en todas sus partes.

Hábitat: Sobre madera muerta de angiospermas. Ocasiona pudrición morena.

Material revisado: CHIAPAS: Medina 63, 126; Valenzuela 4953, 5010 (CONABIO 1335, 1336, 1402, 1403).

Distribución conocida en México: Campeche, Chiapas, Colima, Jalisco, Morelos, Nuevo León, Oaxaca, Querétaro, Quintana Roo, San Luis Potosí, Sierra Madre Oriental, Sonora, Tabasco, Tamaulipas, Veracruz y Yucatán (Bandala et al., 1993; Montaño et al., 2006; Valenzuela et al., 2002, 2006).

Familia Hymenochaetaceae

Fuscoporia callimorpha (Lév.) Groposo, Log.-Leite \& Góes-Neto, Mycotaxon 101: 57 (2007). Figs. 9-12.

Basidioma anual, pileado-sésil, semicircular, aplanado a cóncavo, de consistencia leñosa, de 40-110 X 25-75 X 5-20 mm. Píleo glabro, rugoso, surcado, zonado, de color rojo-tomate a rojo-óxido $(8 \mathrm{C} 8,8 \mathrm{D} 8,8 \mathrm{E} 8)$; margen ondulado, agudo y estéril. Himenóforo con poros de color café claro a color coñac (6E7, 6C8, 6D7, 6D8), ligeramente iridiscentes, pequeños, 7-9 por $\mathrm{mm}$, circulares, con bordes gruesos y 
lisos; tubos del mismo color que el himenóforo, hasta de $2 \mathrm{~mm}$ de longitud, no estratificados. Contexto de color café-anaranjado a café claro (6C8, 6D8), simple, fibroso; sabor y olor no registrados. Sistema hifal dimítico; hifas generativas de 1.6-2.4 $\mu \mathrm{m}$ de diámetro, con septo simple, hialinas a amarillentas, con paredes delgadas a engrosadas, de contenido citoplásmico homogéneo o con gotas refringentes, ramificadas o no; hifas esqueléticas de 3.2-4 $\mu \mathrm{m}$ de diámetro, amarillo-doradas a color café, con paredes gruesas a casi sólidas, algunas con septos secundarios irregulares. Setas de 1.6-2.8 X 1.6-8.8 $\mu \mathrm{m}$, lageniformes a subuladas, de color moreno oscuro, con pared gruesa, acuminadas, rectas. Basidios de 8-12 X 3.2-6.4 $\mu \mathrm{m}$, clavados, hialinos con pared delgada; uni, bi o tetrasporados. Basidiosporas no observadas.

Reacciones macroquímicas: en $\mathrm{KOH}$ a $5 \%$ vira a negro en todas sus partes.

Hábitat: Sobre madera muerta de angiospermas. Ocasiona pudrición blanca.

Material estudiado: CHIAPAS: Medina 1, Valenzuela 4907.

Distribución conocida en México: Chiapas, Jalisco, Sierra Madre Oriental y Tamaulipas (Bandala et al., 1993; Herrera-Fonseca y Guzmán-Dávalos, 2002; Cifuentes et al., 2004).

Phylloporia pectinata (Klotzsch) Ryvarden, Syn. Fung. 5: 196 (1991). Figs. 13-15.

Basidioma perenne, pileado-sésil, aplanado a semiungulado, imbricado, de consistencia leñosa, de 20-110 X 15-60 X 8-25 mm. Píleo surcado, rugoso, zonado en ejemplares viejos, de color gris-café (6F8) a negro; margen glabro, agudo, entero y estéril. Himenóforo con poros de color café claro a avellana (6D8, 6E8), iridiscentes, pequeños, de 8-10 por mm, circulares, con bordes gruesos y lisos; tubos del mismo color que los poros, estratificados, de $1.5 \mathrm{~mm}$ de longitud en estratos individuales, y hasta de $9 \mathrm{~mm}$ en conjunto. Contexto de color café-anaranjado a café claro (6C8, 6D8), hasta de $3 \mathrm{~mm}$ de grosor, fibroso, dúplex, con una costra negra de consistencia dura bajo el píleo; con sabor y olor a tierra. Sistema hifal dimítico; hifas generativas de 1.6-2.4 $\mu \mathrm{m}$ de diámetro, con septos simples, hialinas de color café pálido, con paredes delgadas a medianamente gruesas; hifas esqueléticas de 2.4-4 $\mu \mathrm{m}$ de diámetro, de color café oscuro y paredes gruesas. Setas y otras estructuras himeniales estériles ausentes. Basidios no observados. Basidiosporas de 3.2-4 X 2.8$3.6 \mu \mathrm{m}$, globosas a subglobosas, hialinas a de color moreno-rojizo, inamiloides, con pared delgada a muy gruesa, lisa.

Reacciones macroquímicas: en $\mathrm{KOH}$ a $5 \%$ cambia a negro en todas sus partes, sin aclararse posteriormente.

Hábitat: Sobre madera muerta de angiospermas. Ocasiona pudrición blanca. 

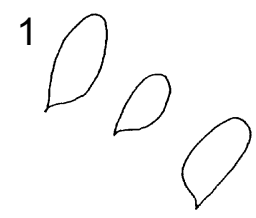
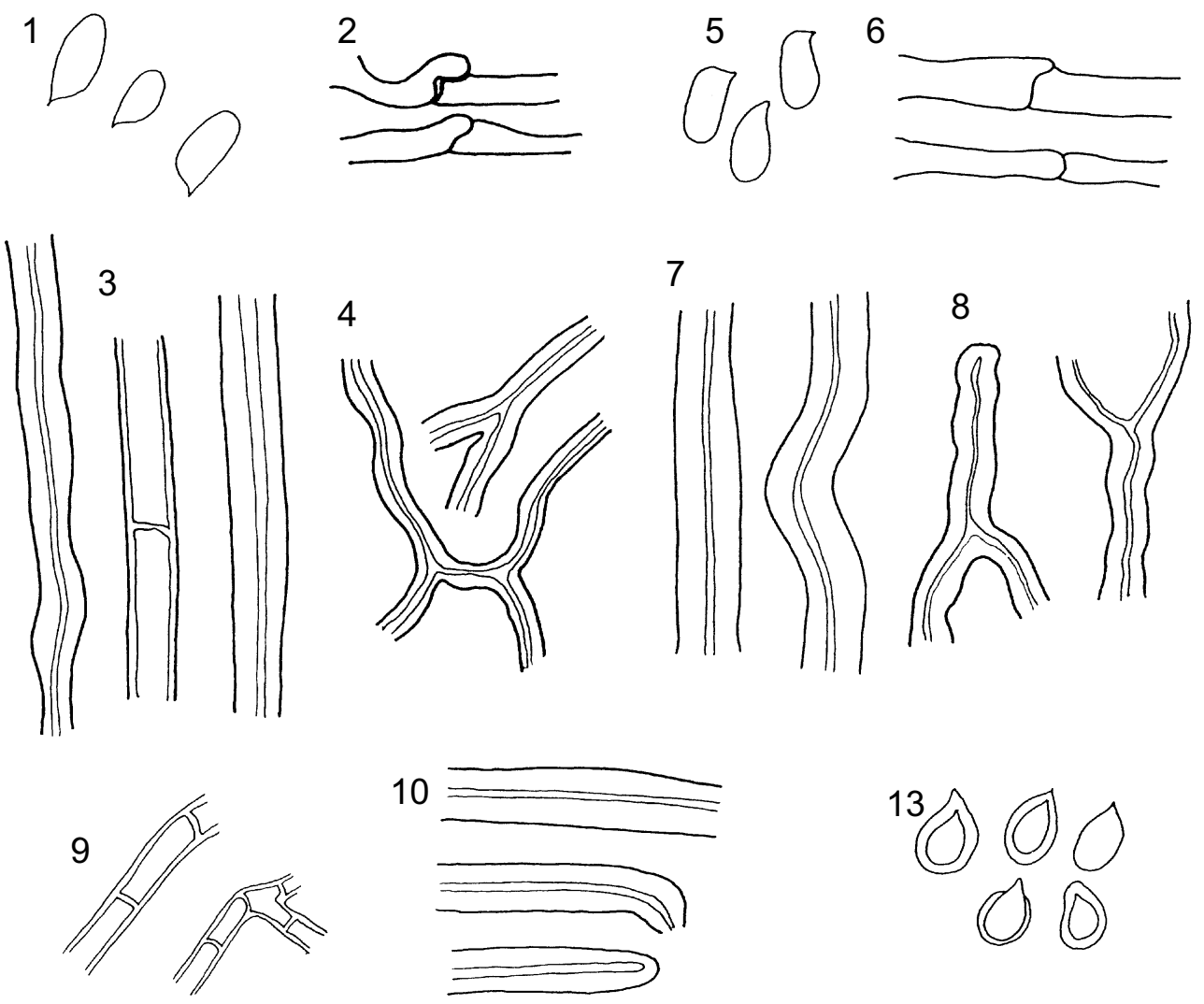

130
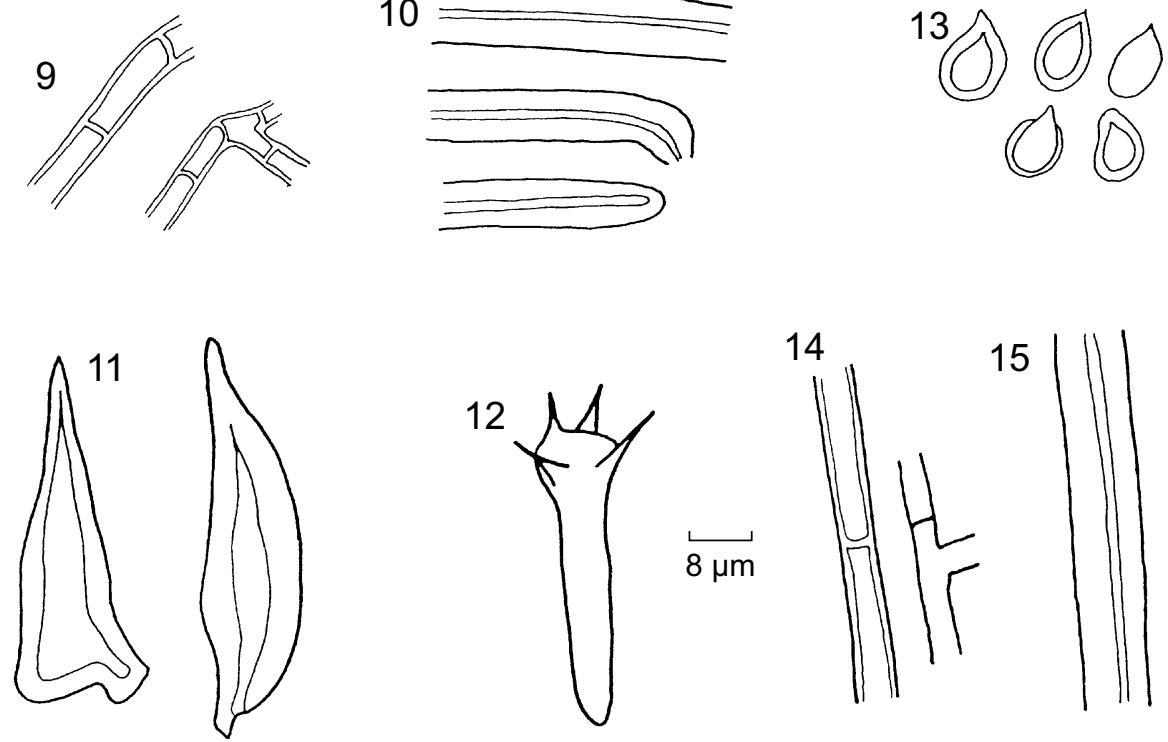

Figs. 1-15. Fomitopsis cupreo-rosea: 1. esporas; 2. hifas generativas; 3. hifas conectivas; 4. hifas esqueléticas. Fomitopsis feei: 5. esporas; 6. hifas generativas; 7. hifas esqueléticas; 8. hifas conectivas. Fuscoporia callimorpha: 9. hifas generativas; 10. hifas esqueléticas; 11. setas lageniformes; 12. basidio clavado. Phylloporia pectinata: 13. esporas; 14. hifas generativas; 15 . hifas esqueléticas. 
Material estudiado: CHIAPAS: Butrón s. n. (diciembre 1985); Medina 23, 112, 121; Valenzuela 4917, 4997, 5006.

Distribución conocida en México: Chiapas, Distrito Federal, Estado de México, Jalisco, Querétaro, Quintana Roo, Sierra Madre Oriental, Tamaulipas, Veracruz y Yucatán (Bandala et al., 1993; Herrera-Fonseca y Guzmán-Dávalos, 2002; Valenzuela et al., 2002; Cifuentes et al., 2004).

Familia Meripilaceae

Hydnopolyporus fimbriatus (Fr.) D.A. Reid, Persoonia 2(2): 151 (1962). Figs. 16-20.

Basidioma anual, sésil o con una constricción basal a manera de estípite, flabeliforme, cespitoso, gregario, imbricado o rosetado, de consistencia correosa, de 5-20 $\mathrm{X}$ 12-30 X 0.5.1 mm. Píleo glabro o finamente velutino en algunas zonas, rugoso, con estrías verticales, blanco a blanquecino-amarillento (1A1, 4A2) con manchas amarilloalbaricoque (5B6); margen agudo, partido, lobado o fimbriado, fértil (tiende a enrollarse en ejemplares secos). Himenóforo con poros blanquecino-amarillentos a amarillo-albaricoque (3A2, 4A3, 5B6), pequeños, de 5-7 por mm, angulares, irpiciformes, regulares o irregulares, con bordes delgados y dentados; tubos del mismo color que los poros, hasta de $1 \mathrm{~mm}$ de longitud, no estratificados. Estípite hasta de $5 \times 1 \mathrm{~mm}$, lateral, concolor con el píleo y de la misma textura y consistencia, sólido. Contexto blanco (1A1), hasta de $0.5 \mathrm{~mm}$ de grosor, simple, fibroso; con olor y sabor fúngico. Sistema hifal monomítico; hifas generativas de 2.4-4 $\mu \mathrm{m}$ de diámetro, con septo simple, hialinas, con paredes delgadas, con ramificaciones o sin ellas; hifas generativas esqueletizadas, de 4.8-6.4 $\mu \mathrm{m}$ de diámetro, sin septo o con septos simples esporádicos, hialinas, con paredes gruesas a casi sólidas, rectas, no ramificadas; hifas generativas esqueletizadas, de 1.6-6 $\mu \mathrm{m}$ de diámetro, hialinas, con paredes gruesas, sinuosas, de tipo dendroide (profusamente ramificadas). Cistidios y otros elementos himeniales estériles ausentes. Basidios no observados. Basidiosporas de 3.2-4.8 X 1.6-3.2 $\mu \mathrm{m}$, subglobosas a elipsoides, hialinas, inamiloides, con pared delgada, lisas. Conidios de 2.8-6 X 2-5 $\mu \mathrm{m}$, globosos a elipsoides, hialinos, inamiloides, con pared delgada a gruesa, lisas.

Reacciones macroquímicas: en $\mathrm{KOH}$ a $5 \%$ es negativo en todas sus partes. Hábitat: Sobre madera muerta de angiospermas. Ocasiona pudrición blanca. Material revisado: CHIAPAS: Medina 71, Valenzuela 4958 (CONABIO 1368, 1436).

Distribución conocida en México: Campeche, Chiapas, Estado de México, Distrito Federal, Durango, Estado de México, Hidalgo, Jalisco, Michoacán, More- 
los, Oaxaca, Puebla, Querétaro, San Luis Potosí, Sierra Madre Oriental, Tamaulipas, Tlaxcala y Veracruz (Bandala et al., 1993; Guzmán-Dávalos y Fragosa-Díaz, 1994; Rodríguez et al., 1994; Nava y Valenzuela, 1997; Herrera-Fonseca y GuzmánDávalos, 2002; Valenzuela et al., 2002; Raymundo y Valenzuela, 2003; Cifuentes et al., 2004; Díaz-Moreno et al., 2005; Landeros et al., 2006).

Rigidoporus microporus (Sw.) Overeem, Icon. Fung. Malay. 5: 1 (1924). Figs. 2123.

Basidioma anual, sésil a dimidiado, plano, solitario a disperso, de consistencia corchosa, de 160 X 70 X $30 \mathrm{~mm}$. Píleo glabro, rugoso, poco surcado, de color crema a amarillo-albaricoque (3A2, 4A3, 5B6); margen glabro, obtuso, entero a poco ondulado, estéril. Himenóforo con poros de color anaranjado-mandarina a morenoanaranjado (6B8, 6C8), muy pequeños, de $8-10$ por $\mathrm{mm}$, angulares, regulares, con bordes gruesos y lisos; tubos de color blanquecino-amarillento a anaranjado brillante (4A2, 5A5), hasta de $4 \mathrm{~mm}$ de longitud, no estratificados. Contexto del mismo color que los tubos, hasta de $25 \mathrm{~mm}$ de grosor, fibroso, acuoso, simple; con sabor y olor fúngico. Sistema hifal monomítico; hifas generativas de (1.6-) 2.4-4.8 $\mu \mathrm{m}$ de diámetro, con septos simples, hialinas, con paredes delgadas a gruesas, rectas a poco sinuosas, simples o ramificadas. Cistidiolos de 17.6-24 X 8-10.4 $\mu \mathrm{m}$, lectiformes, mucronados, hialinos, con pared delgada, lisos. Basidios no observados. Basidiosporas de 3.2-4.8 X 3.2-4 $\mu \mathrm{m}$, subglobosas, hialinas, inamiloides, con pared delgada, lisas.

Reacciones macroquímicas: en $\mathrm{KOH}$ a 5\% cambia a color café claro en todas sus partes.

Hábitat: Sobre madera muerta de angiospermas. Ocasiona pudrición blanca.

Material revisado: CHIAPAS: Medina 125 (CONABIO 1382).

Distribución conocida en México: Distrito Federal, Jalisco, Nuevo León, Oaxaca, Península de Baja California, Oaxaca, Querétaro, Quintana Roo, Sonora, Tamaulipas y Veracruz (Bandala et al., 1993; Herrera-Fonseca y Guzmán-Dávalos, 2002; Valenzuela et al., 2002; Raymundo y Valenzuela, 2003).

Rigidoporus ulmarius (Sowerby) Imazeki, Bull. Gov. Forest Exp. St. Tokyo 57: 119 (1952). Figs. 24-26.

Basidioma anual, sésil a efuso-reflejo, plano a convexo, solitario, de consistencia corchosa, de 30-400 X 25-250 X 15-70 mm. Píleo glabro, rugoso, zonado, de 
color amarillo-melón (5A6) con tonalidades anaranjadas brillantes, blanco-anaranjadas y amarillo-anaranjadas $(5 \mathrm{~A} 4,5 \mathrm{~A} 2,3 \mathrm{~A} 2)$, puede presentar tonalidades verdosas ocasionadas por algas; margen obtuso, ondulado y fértil. Himenóforo con poros blanquecino-amarillentos (3A2), pequeños, de 7-9 por mm, angulares, irregulares, con bordes gruesos, lisos; tubos del mismo color que el himenóforo, hasta de 5 $\mathrm{mm}$ de longitud, no estratificados. Contexto blanco (3A1), de 4-60 mm de grosor, fibroso, acuoso, simple; con sabor y olor fúngico. Sistema hifal monomítico; hifas generativas de 1.6-4.8 $\mu \mathrm{m}$ de diámetro, con septos simples, hialinas a amarillentas, con paredes delgadas a gruesas, rectas a poco sinuosas, simples o ramificadas. Cistidiolos de 16-26.4 X 5.6-6.4 $\mu \mathrm{m}$, clavados a ventricosos, hialinos, con pared delgada, lisos. Basidios no observados. Basidiosporas de 5.6-8 $\mu \mathrm{m}$ de diámetro, globosas, hialinas a amarillentas, inamiloides, con citoplasma homogéneo o heterogéneo, frecuentemente colapsadas en ejemplares herborizados, con pared delgada, lisas.

Reacciones macroquímicas: en $\mathrm{KOH}$ a $5 \%$ no presenta ningún cambio.

Hábitat: Sobre madera muerta de angiospermas. Ocasiona pudrición morena. Material revisado: CHIAPAS: Medina 152; Valenzuela 4909, 5012 (CONABIO 1383, 1460, 1664).

Distribución conocida en México: Chiapas, Chihuahua, Michoacán, Nuevo León, Oaxaca, Querétaro, Sierra Madre Oriental, Tabasco, Veracruz (Bandala et al., 1993; Valenzuela et al., 2002; Raymundo y Valenzuela, 2003; Cifuentes et al., 2004; Chanona-Gómez et al., 2007; Díaz-Moreno et al., 2009).

Familia Meruliaceae

Gloeoporus thelephoroides (Hook.) G. Cunn., Bull. N.Z. Dept. Sci. Industr. Res., Pl. Dis. Div. 164: 111 (1965). Figs. 27-31.

Basidioma anual, pileado-sésil, flabeliforme a dimidiado, plano a ligeramente convexo, gregario a imbricado, de consistencia subcarnosa, de 50-150 X 30-80 X 1-2 mm. Píleo finamente velutino, surcado a ligeramente zonado, blanco con tonos blanquecino-amarillentos (3A2); margen agudo, ondulado y estéril. Himenóforo con poros blanco-anaranjados a blanco-rosáceos (5A2), pequeños, de 6-8 por mm, circulares, con bordes gruesos y lisos; tubos blancos con tonos blanco-anaranjados, hasta de $1 \mathrm{~mm}$ de grosor. Contexto hasta de $1 \mathrm{~mm}$ de grosor, blanco, fibroso, con una capa translúcida contigua al himenóforo, de consistencia gelatinosa en fresco y cerosa cuando el ejemplar está herborizado; sabor y olor no perceptibles. Sistema hifal monomítico; hifas generativas de 2-4 $\mu \mathrm{m}$ de diámetro, con septos simples, hiali- 

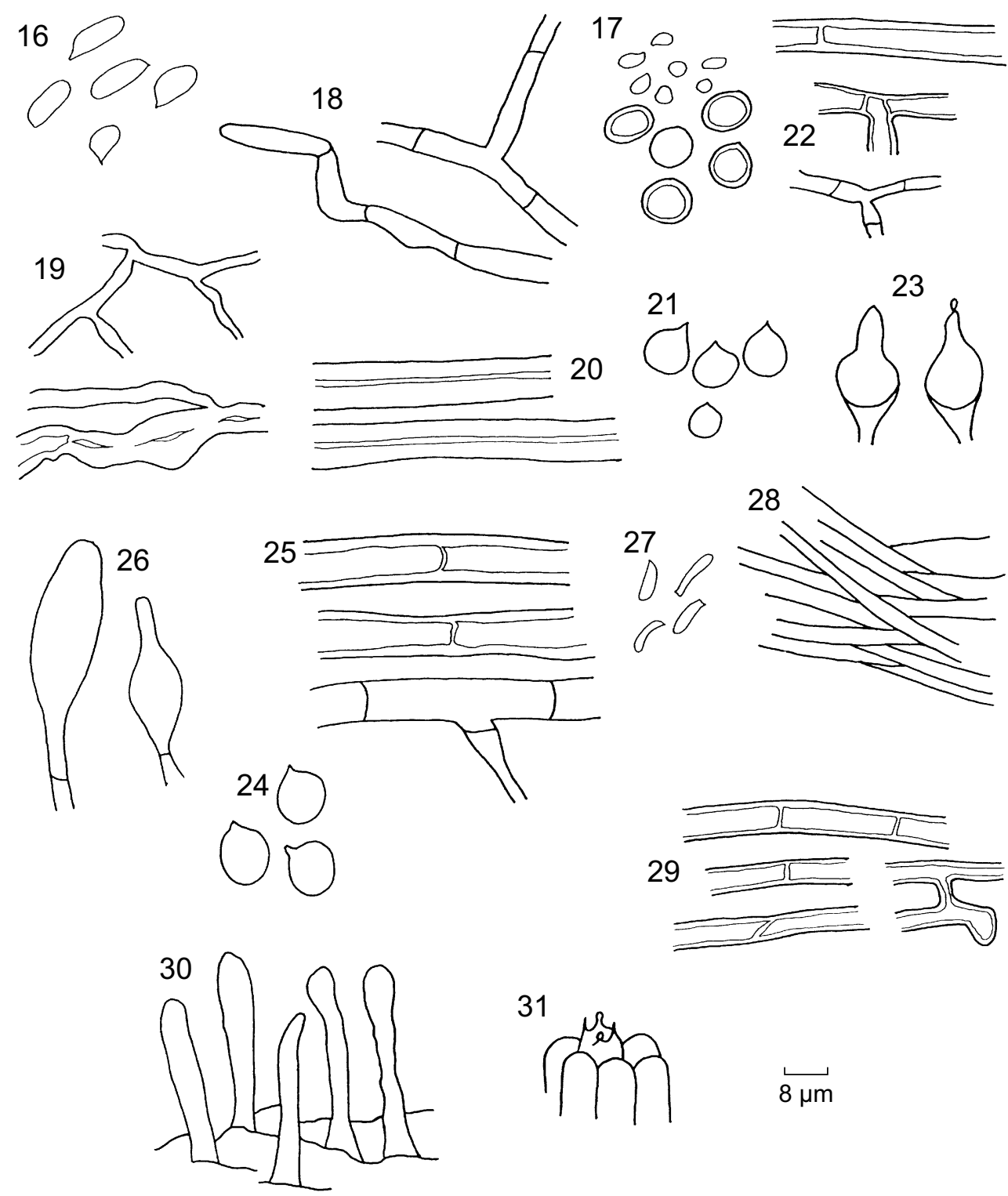

31

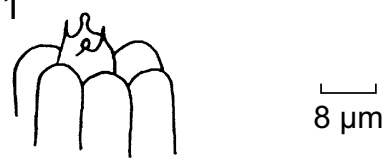

Figs. 16-31. Hydnopolyporus fimbriatus: 16. esporas; 17. conidios; 18. hifas generativas; 19. hifas conectivas; 20 . hifas esqueléticas. Rigidoporus microporus: 21 . basidiosporas; 22 . hifas generativas; 23. cistidiolos. Rigidoporus ulmarius: 24. basidiosporas; 25 . hifas generativas; 26. cistidiolos. Gloeoporus thelephoroides: 27. basidiosporas; 28. hifas generativas de pared delgada; 29. hifas generativas de pared gruesa; 30 . terminaciones hifales proyectadas en himenio; 31 . basidio. 
nas, con paredes delgadas a gruesas, algunas gelatinizadas y refringentes, con o sin ramificaciones. Cistidios y otros elementos himeniales estériles ausentes, aunque algunas terminaciones hifales se llegan a proyectar a través del himenóforo dando la apariencia de estructuras himeniales estériles. Basidios de 3.2 X $1.2 \mu \mathrm{m}$, cilíndricos a ligeramente clavados, hialinos, con paredes delgadas, lisos, tetrasporados, con esterigmas de $0.5 \mu \mathrm{m}$ de longitud. Basidiosporas de 3.2-3.6 X 0.8-1.6 $\mu \mathrm{m}$, cilíndricas a alantoides, hialinas, inamiloides, con pared delgada, lisas.

Reacciones macroquímicas: el píleo y el contexto cambian a amarillo-anaranjado; el himenóforo cambia a amarillo-verdoso y posteriormente a color café.

Hábitat: Sobre madera muerta de angiospermas. Ocasiona pudrición blanca.

Material revisado: CHIAPAS: Medina 86, 145, 151; Valenzuela 4974, 5026, 5036.

Distribución conocida en México: Solamente se conocía de Oaxaca (Raymundo y Valenzuela, 2003).

Familia Polyporaceae

Coriolopsis brunneoleuca (Berk.) Ryvarden, Norw. Jl. Bot. 19: 230 (1972). Figs. 32-35.

Basidioma anual, pileado-sésil a efuso-reflejo, aplanado, semicircular, gregario, de consistencia correosa, de 15-150 X 10-100 X $2.5 \mathrm{~mm}$. Píleo tomentoso a escruposo, blanco-amarillento a de color arena (2A2, 4B3); margen blanco-lechoso a de color crema (1A2, 4A3), crenado, agudo y estéril. Himenóforo con poros color de crema a café claro (4A3, 4B3), pequeños a medianos, de 2-4 por mm, angulares, con bordes ligeramente engrosados y ondulados; tubos de color crema a bayo (4A3, $4 \mathrm{C} 3$ ), hasta de $2 \mathrm{~mm}$ de longitud, no estratificados, en superficies no horizontales se observan escalonados. Contexto del mismo color que los tubos, hasta de $1 \mathrm{~mm}$ de grosor, fibroso, simple; con sabor y olor fúngico. Sistema hifal trimítico; hifas generativas de 1.2-2.6 $\mu \mathrm{m}$ de diámetro, fibuladas, hialinas, con paredes delgadas a ligeramente engrosadas, ramificadas; hifas esqueléticas de 2.6-4.8 $\mu \mathrm{m}$ de diámetro, hialinas a amarillentas, con paredes gruesas a sólidas, presentan una reacción dextrinoide en conjunto; hifas conectivas de 1.3-3.2 $\mu \mathrm{m}$ de diámetro, hialinas a amarillentas, con paredes gruesas a casi sólidas. Cistidios y otros elementos himeniales estériles ausentes. Basidios no observados. Basidiosporas de 7.2-12.4 X 2.4-4.8 $\mu \mathrm{m}$, elipsoides a cilíndricas, hialinas, inamiloides, con pared delgada, lisa.

Reacciones macroquímicas: vira a color moreno en todas sus partes. 
Hábitat: Sobre madera muerta de angiospermas. Ocasiona pudrición blanca.

Material estudiado: CHIAPAS: Medina 12, 93; Valenzuela 4932, 4980, 5003 (CONABIO 1300, 1301, 1367, 1368, 1381).

Distribución conocida en México: Especie muy común, se conoce de Campeche, Chiapas, Chihuahua, Colima, Durango, Hidalgo, Jalisco, Michoacán, Morelos, Oaxaca, Puebla, Querétaro, Quintana Roo, San Luis Potosí, Sierra Madre Oriental, Sinaloa, Sonora, Tabasco, Tamaulipas, Veracruz y Yucatán (Bandala et al., 1993; Guzmán-Dávalos y Fragosa-Díaz, 1994; Rodríguez et al., 1994; Herrera-Fonseca y Guzmán-Dávalos, 2002; Valenzuela et al., 2002; Raymundo y Valenzuela, 2003; Cifuentes et al., 2004; Díaz-Moreno et al., 2009).

Coriolopsis byrsina (Mont.) Ryvarden, Norw. Jl. Bot. 19: 230 (1972). Figs. 36-39.

Basidioma anual, resupinado a efuso-reflejo, circular a semicircular, disperso a gregario, de consistencia correosa, de 60-170 X 30-85 X $2.5 \mathrm{~mm}$. Píleo aterciopelado, surcado, de color amarillo-linóleo a color arcilla, con tonalidades de color miel a coñac (5D5, 5D6, 5E7, 6E7), margen agudo, ondulado a ligeramente crenado, pubescente, estéril. Himenóforo con poros anaranjados claros a de color champaña (4B4, 5A4), pequeños a medianos, de 3-6 por mm, circulares, con bordes gruesos y lisos; tubos concoloros con los poros, hasta de $0.5 \mathrm{~mm}$ de longitud, no estratificados. Contexto anaranjado-grisáceo, de color dorado-rojizo o café-anaranjado (5B4, 6C7, 6C8), hasta de $0.5 \mathrm{~mm}$ de grosor, simple, fibroso, correoso; con sabor y olor no perceptibles. Sistema hifal trimítico; hifas generativas de 1.2-2.8 $\mu \mathrm{m}$ de diámetro, con fíbulas, hialinas, con paredes delgadas, ramificadas o no; hifas esqueléticas de 1.6-4-8 $\mu \mathrm{m}$ de diámetro, amarillentas, con paredes gruesas a casi sólidas, sin septos o con septos simples esporádicos; hifas conectivas de 1.6-3.2 $\mu \mathrm{m}$ de diámetro, amarillentas, con paredes gruesas a sólidas, sinuosas. Cistidios y otros elementos himeniales estériles ausentes. Basidios no observados. Basidiosporas de 7.2-12 X 4.2-5.6 $\mu \mathrm{m}$, elipsoides a subcilíndricas, hialinas, inamiloides, con pared delgada, lisa.

Reacciones macroquímicas: el píleo y el contexto cambian a negro y posteriormente a color moreno; el himenóforo cambia a color moreno oscuro y minutos después se aclara.

Hábitat: Sobre madera muerta de angiospermas. Ocasiona pudrición blanca.

Material revisado: CHIAPAS: Medina 18, 65, 88, 134; Valenzuela 4915, 4955, 4976, 5018 (CONABIO 1305, 1306, 1307, 1309, 1973, 1375, 1376, 1377, abril 2 1986).

Distribución conocida en México: Chiapas, Hidalgo, Oaxaca, Querétaro, Quintana Roo, Sierra Madre Oriental, Tabasco, Tamaulipas, Veracruz y Yucatán 
(Bandala et al., 1993; Chacón y Guzmán, 1994; Valenzuela et al., 2002; Raymundo y Valenzuela, 2003; Cifuentes et al., 2004).

Coriolopsis caperata (Berk.) Murrill, N. Amer. Fl. 9(2): 77 (1908). Figs. 40-44.

Basidioma anual, efuso-reflejo a pileado-sésil, semicircular a dimidiado, plano a cóncavo, gregario, de consistencia corchosa, de 30-200 X 25-70 X 5-10 mm. Píleo escruposo, tomentoso, sulcado, de color café-amarillento a gris-café (5D8, 6E8, 6F8); margen de color crema a café claro (1A2, 6D8), agudo, ondulado a crenado, estéril. Himenóforo con poros amarillo-dorados a amarillo-rojizos $(4 \mathrm{C} 4,5 \mathrm{C} 4)$, pequeños, de 3-5 por mm, angulares, con bordes ligeramente gruesos y lisos; tubos amarillodorados a de color café-amarillento (4C4, 5C4 5D8), hasta de $2 \mathrm{~mm}$ de longitud, no estratificados. Contexto de color amarillo-dorado a café-cacao $(4 \mathrm{C} 4,5 \mathrm{C} 8)$, hasta de 2 $\mathrm{mm}$ de grosor, fibroso, con una costra negra bajo el tomento; con sabor y olor no perceptibles. Sistema hifal trimítico; hifas generativas de 1.6-2.4 $\mu \mathrm{m}$ de diámetro, fibuladas, hialinas, con paredes delgadas; hifas esqueléticas sin septos, amarillo-doradas, de 2.4-5.6 $\mu \mathrm{m}$ de diámetro, con paredes delgadas a sólidas, también se encontraron hifas esqueléticas de 1.6-4 $\mu \mathrm{m}$ de diámetro, con septos simples regularmente espaciados, con paredes delgadas, de color amarillo-dorado, rectas a sinuosas, ramificadas o no; hifas conectivas de 1.6-3.2 $\mu \mathrm{m}$ de diámetro, hialinas a amarillentas, con paredes gruesas a sólidas, sinuosas y muy ramificadas. Cistidios y otros elementos himeniales estériles ausentes. Basidios no observados. Basidiosporas de 7.2-9.6 X 2.4-4 $\mu \mathrm{m}$, elipsoides a cilíndricas, hialinas, inamiloides, lisas, con paredes delgadas.

Reacciones macroquímicas: el contexto y el píleo cambian a negro, el himenóforo cambia a color café muy oscuro.

Hábitat: Sobre madera muerta de angiospermas. Ocasiona pudrición blanca.

Material revisado: CHIAPAS: Medina 128, Valenzuela 5012 (CONABIO 1313, 1379).

Distribución conocida en México: Campeche, Chiapas, Colima, Hidalgo, Morelos, Oaxaca, Quintana Roo, Sierra Madre Oriental, Tabasco y Veracruz (Bandala et al., 1993; Ryvarden y Guzmán, 1993; Raymundo y Valenzuela, 2003; Cifuentes et al., 2004).

Coriolopsis polyzona (Pers.) Ryvarden, Norw. Jl. Bot. 19: 230 (1972). Figs. 45-48.

Basidioma anual, pileado-sésil, dimidiado, gregario, de consistencia correosa, de 60-110 X 45-65 X 8-12 mm. Píleo tomentoso, sulcado, dorado a amarillo-man- 

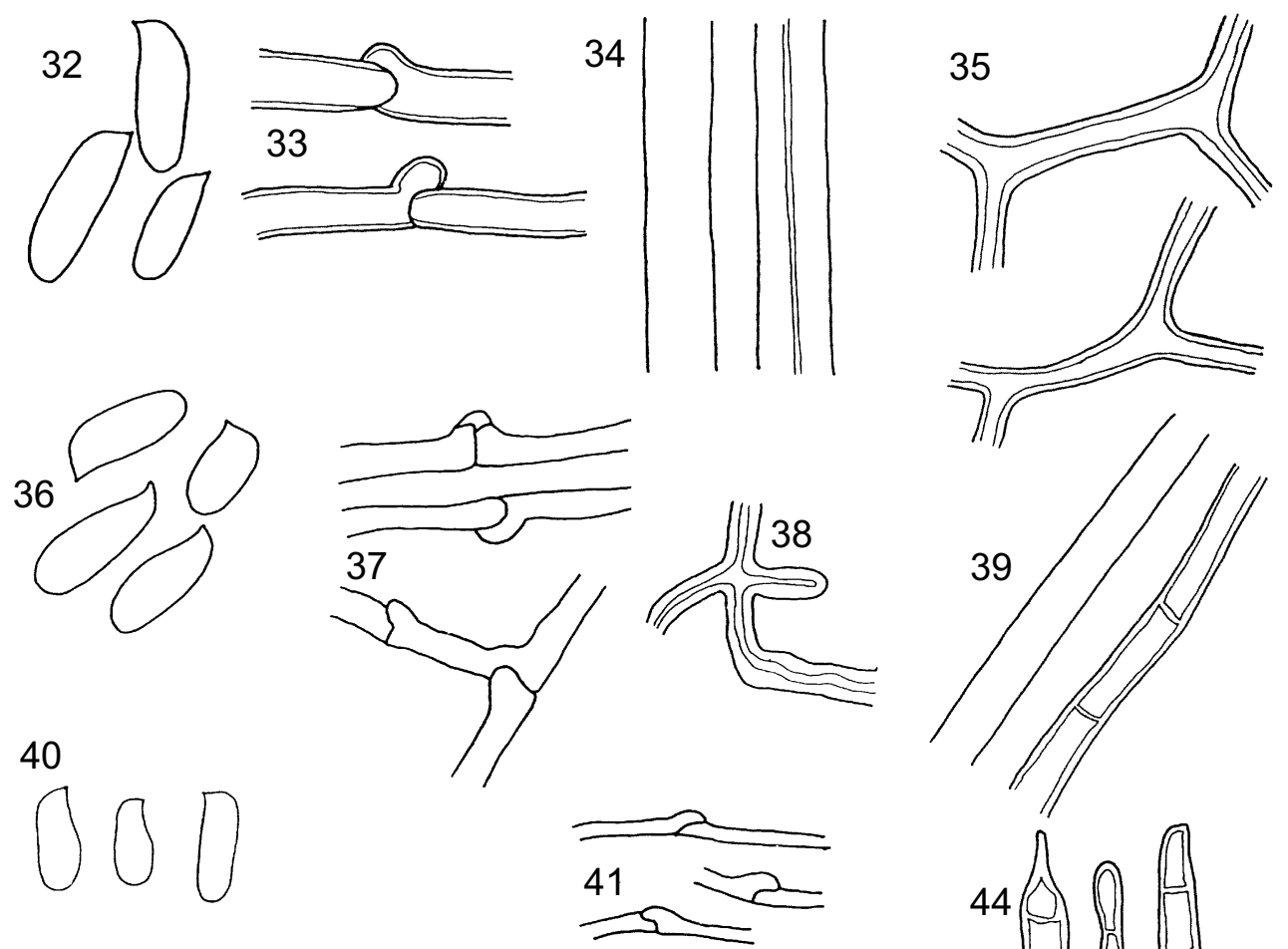

42
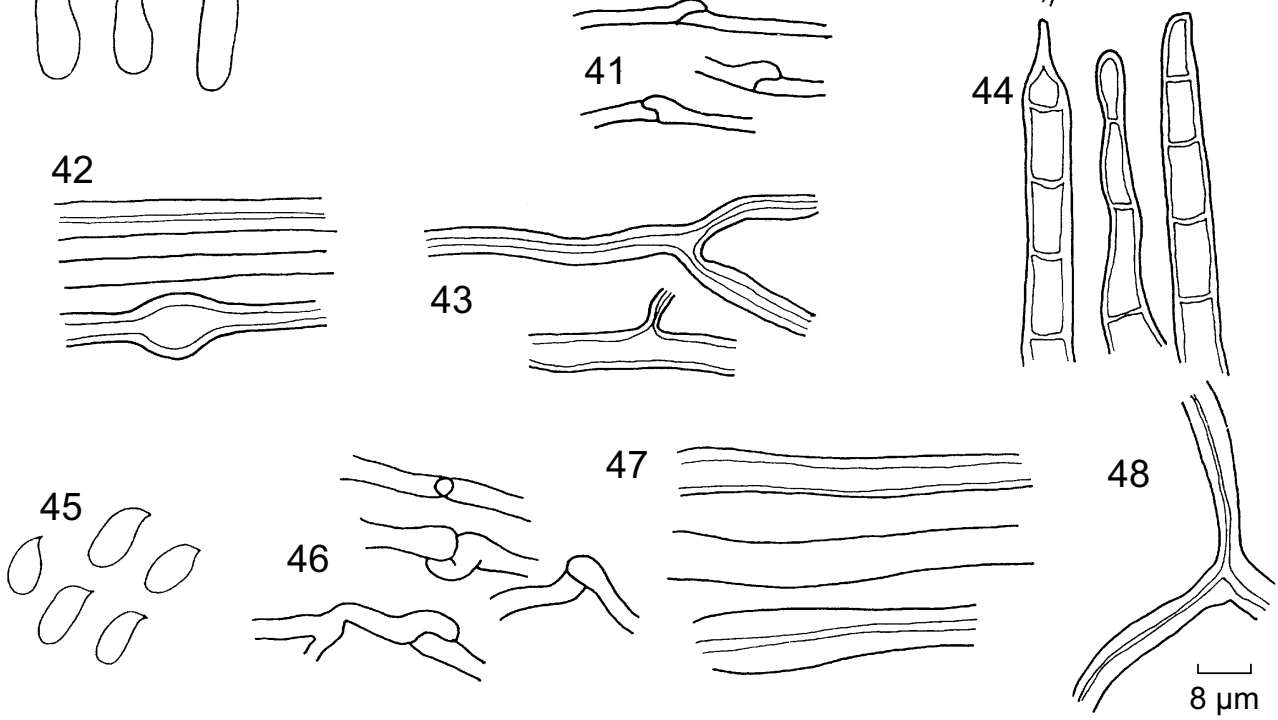

Figs. 32-48. Coriolopsis brunneo-leuca: 32. basidiosporas; 33. hifas generativas; 34. hifas esqueléticas; 35. hifas conectivas. Coriolopsis byrsina: 36. basidiosporas; 37. hifas generativas; 38. hifas conectivas; 39. hifas esqueléticas. Coriolopsis caperata: 40. basidiosporas; 41. hifas generativas; 42. hifas esqueléticas sin septos; 43. hifas conectivas; 44. hifas esqueléticas septadas. Coriolopsis polyzona: 45 . basidiosporas; 46. hifas generativas; 47. hifas esqueléticas; 48. hifas conectivas. 
tequilla (4C6, 4A5), margen agudo, ondulado y estéril. Himenóforo con poros de color crema a champaña (4B4, 4A3), medianos, 2-3 por mm, circulares a angulares, irregulares, con bordes medianos y lisos a ligeramente ondulados; tubos concoloros con los poros, hasta de $2 \mathrm{~mm}$ de longitud, no estratificados. Contexto de color crema a amarillo pálido (4A3), hasta de $1 \mathrm{~mm}$ de grosor, fibroso, esponjoso, con una capa color café obscuro bajo el tomento; sabor y olor no resgistrados. Sistema hifal trimítico; hifas generativas de 1.6-3.2 $\mu \mathrm{m}$ de diámetro hialinas, con fíbulas, con paredes delgadas; hifas esqueléticas de 2.4-4 $\mu \mathrm{m}$ de diámetro en himenóforo y de 4.8-7.2 $\mu \mathrm{m}$ de diámetro en contexto, hialinas a amarillentas, con paredes gruesas a casi sólidas; hifas conectivas de 1.6-3.2 $\mu \mathrm{m}$ de diámetro, hialinas, con paredes gruesas, algunas sinuosas. Tomento del píleo formado por hifas esqueléticas aglutinadas, con paredes muy gruesas. Cistidios y otros elementos himeniales estériles ausentes. Basidios no observados. Basidiosporas de 4.8-6.4 X 2.4-3.2 $\mu \mathrm{m}$, elipsoides, hialinas, inamiloides, con pared delgada.

Reacciones macroquímicas: el píleo y el contexto cambian a color café, el himenóforo cambia a sepia, posteriormente se aclaran.

Hábitat: Sobre madera muerta de angiospermas. Ocasiona pudrición blanca.

Material revisado: CHIAPAS: Medina 164, Valenzuela s. n. (CONABIO 1394, abril 3, 1986).

Distribución conocida en México: Campeche, Chiapas, Chihuahua, Colima, Durango, Hidalgo, Jalisco, Michoacán, Morelos, Oaxaca, Puebla, Querétaro, Quintana Roo, San Luis Potosí, Sierra Madre Oriental, Sinaloa, Sonora, Tabasco, Tamaulipas, Veracruz y Yucatán (Bandala et al., 1993; Guzmán-Dávalos y FragosaDíaz, 1994; Rodríguez et al., 1994; Esqueda-Valle et al., 1999; Herrera-Fonseca y Guzmán-Dávalos, 2002; Valenzuela et al., 2002; Raymundo y Valenzuela, 2003; Cifuentes et al., 2004; Díaz-Moreno et al., 2009).

Earliella scabrosa (Pers.) Gilb. \& Ryvarden, Mycotaxon 22(2): 364 (1985). Figs. 49-52.

Basidioma anual o bienal, pileado-sésil, efuso-reflejo o resupinado, plano a cóncavo, semicircular, disperso a gregario, de consistencia corchosa a leñosa, de 20-400 X 100 X 5-40 mm. Píleo glabro a velutino, zonado, rugoso, con una cutícula dura y rojiza cerca de la base, el resto del píleo es blanco-lechoso o blanco-amarillento y amarillo-mantequilla (1A2, 4A5), cambia a anaranjado-grisáceo (5B4) al tocarlo; margen obtuso, irregularmente ondulado y estéril. Himenóforo con poros de color crema a amarillo-mantequilla (4A3, 4A4, 4A5), de 1-2 por mm, angula- 
res, muy irregulares (llega a presentar himenóforo laberitinforme en algunas zonas), bordes medianamente gruesos, lisos o dentados; tubos concoloros con el himenóforo, hasta de $2.5 \mathrm{~mm}$ de longitud, no estratificados, en zonas decurrentes se observan escalonados. Contexto amarillo pálido a amarillo claro o blanco-lechoso (4A3, 4A4, 1A2), hasta de $3 \mathrm{~mm}$ de grosor, algodonoso, simple; sabor ligeramente picante, olor fúngico desagradable. Sistema hifal trimítico; hifas generativas de 1.6-3.2 $\mu \mathrm{m}$ de diámetro, con fíbulas, hialinas, con paredes delgadas; hifas esqueléticas de 2.4-4 $\mu \mathrm{m}$ de diámetro, hialinas, con paredes gruesas a sólidas, rectas o sinuosas; hifas conectivas de 1.6-3.2 $\mu \mathrm{m}$ de diámetro, hialinas, con paredes gruesas, muy ramificadas. Cistidios y otros elementos himeniales estériles ausentes. Basidios no observados. Basidiosporas de 9.6-11.2 X 2.4-4 $\mu \mathrm{m}$, elipsoides, hialinas, inamiloides, con pared delgada, lisas.

Reacciones macroquímicas: la cutícula cambia a negro, el resto del píleo, el himenóforo y el contexto cambian a color café claro.

Hábitat: Sobre madera muerta de angiospermas. Ocasiona pudrición blanca.

Material revisado: CHIAPAS: Medina 25, 97, 116, 117, 127, 133; Valenzuela 4984, 5000, 5002, 5011, 5015, 5017 (CONABIO 1317, 1318, 1319, 1320, 1321, 1322, 1390, 1391, 1392, 1393, 1394, 1396).

Distribución conocida en México: Campeche, Chiapas, Colima, Hidalgo, Oaxaca, Puebla, Querétaro, Quintana Roo, Sierra Madre Oriental, Tabasco, Tamaulipas, Veracruz y Yucatán (Bandala et al., 1993; Valenzuela et al., 2002; Raymundo y Valenzuela, 2003; Cifuentes et al., 2004; Chanona-Gómez et al., 2007).

Favolus tenuiculus P. Beauv., Fl. Oware. 1(8): 74 (1806). Figs. 53-55.

Basidioma anual, pileado-sésil o con una constricción a manera de estípite, flabeliforme, gregario, de consistencia carnosa, de 13-30 X 10-35 X 1.5-5 mm. Píleo glabro a finamente velutino, escamoso hacia la base, blanco a amarillo sólido (2A2, $3 \mathrm{~A} 2,4 \mathrm{~A} 2)$; margen entero, agudo y fértil. Himenóforo con poros blancos a de color amarillo pastel (2A2, 2A3, 3A2, 3A3, 3A4), grandes, de 1-4 mm de diámetro, irregulares en tamaño, hexagonales, radialmente alargados, con bordes delgados y lisos a ligeramente crenados; tubos blancos a de color amarillo pastel (3A2, 3A4), no estratificados, hasta de $3 \mathrm{~mm}$ de longitud. Estípite de 7-15 X 1-4 mm, lateral, velutino a escamoso, amarillo pálido a amarillo sólido (3A4, 4A4), de consistencia carnosa. Contexto blanco a blanco-amarillento (3A2), hasta $0.5 \mathrm{~mm}$ de grosor, simple, fibroso; con sabor y olor fúngico. Sistema hifal dimítico; hifas generativas de 1.6-3.2 $\mu \mathrm{m}$ de diámetro, con septo simple, hialinas, con paredes delgadas a medianamente 
gruesas; hifas conectivas de 1.6-4.8 $\mu \mathrm{m}$ de diámetro, hialinas, con paredes gruesas a sólidas, sinuosas, profusamente ramificadas. Cistidios y otros elementos himeniales estériles ausentes. Basidios no observados. Basidiosporas de 8.8-12 X 2.8-3.6 (-4) $\mu \mathrm{m}$, cilíndricas, hialinas, inamiloides, con pared delgada, lisas.

Reacciones macroquímicas: la reacción es negativa en todas sus partes.

Hábitat: Sobre madera muerta de angiospermas, causando pudrición blanca.

Material revisado: CHIAPAS: Medina 83, Valenzuela 4969 (CONABIO 1330, 1446).

Distribución conocida en México: Muy común, se conoce de Campeche, Chiapas, Colima, Estado de México, Hidalgo, Jalisco, Michoacán, Morelos, Nuevo León, Oaxaca, Puebla, Querétaro, Quintana Roo, Sierra Madre Oriental, Tabasco, Tamaulipas y Veracruz (Bandala et al., 1993; Nava y Valenzuela, 1997; Valenzuela et al., 2002; Raymundo y Valenzuela, 2003; Cifuentes et al., 2004; Chanona-Gómez et al., 2007).

Fomes fasciatus (Sw.) Cooke, Grevillea. 14(69): 21 (1885). Figs. 56-59.

Basidioma perenne, pileado-sésil, ungulado, gregario, de consistencia leñosa, de 40-75 X 30-55 X 25-45 mm. Píleo glabro, rugoso, zonado y ligeramente agrietado, de color café-olivo (4D8) con tonos negros y amarillos flor de ranúnculo (4A7) en las partes más jóvenes, en ocasiones se observan tonalidades verdosas por la presencia de algas; margen entero, agudo a obtuso, estéril. Himenóforo con poros de color café hoja otoñal a color café rojizo (6D7, 7E8), pequeños, de 5-8 por mm, angulares a circulares, con bordes delgados a medianamente gruesos y lisos; tubos de color café-amarillento a café-linóleo (5E7, 5E8), estratificados, de $2 \mathrm{~mm}$ de longitud en estratos individuales y de 2-15 mm en conjunto. Contexto de color café-amarillento a amarillo-café $(5 \mathrm{C} 8,5 \mathrm{D} 8)$, de 10-25 $\mathrm{mm}$ de grosor, fibroso, con una capa negra, dura y brillante bajo el píleo; con olor butírico ligero (rancio) y sabor farináceo. Sistema hifal trimítico; hifas generativas de 1.6-4 $\mu \mathrm{m}$ de diámetro, fibuladas, hialinas, con paredes delgadas; hifas esqueléticas de 3.2-6.4 $\mu \mathrm{m}$ de diámetro, amarillentas, con paredes gruesas a sólidas, pueden presentar septos simples irregularmente espaciados; hifas conectivas de 1.6-2 $\mu \mathrm{m}$ de diámetro, hialinas, con paredes gruesas, ramificadas y sinuosas. Cistidios y cistidiolos no observados. Basidios no observados. Basidiosporas de 12.0-13.6 X 4.0-4.8 $\mu \mathrm{m}$, elipsoides a cilíndricas, hialinas, inamiloides, lisas, con pared delgada, con citoplasma granular.

Reacciones macroquímicas: cambia a negro en todas sus partes.

Hábitat: Parásito de angiospermas. Ocasiona pudrición blanca. 
Material revisado: CHIAPAS: Medina 58, Valenzuela 4948 (CONABIO 1332, 1398).

Distribución conocida en México: Muy común, se conoce en Campeche, Chiapas, Chihuahua, Hidalgo, Jalisco, Nayarit, Oaxaca, Puebla, Quintana Roo, Sierra Madre Oriental, Sonora, Tamaulipas, Veracruz (Bandala et al., 1993; GuzmánDávalos y Fragosa-Díaz, 1994; Esqueda-Valle et al., 1999; Raymundo y Valenzuela, 2003; Cifuentes et al., 2004; Díaz-Moreno et al., 2009).

Hexagonia hydnoides (Sw.) M. Fidalgo, Mem. N. Y. Bot. Gdn. 17: 64 (1968). Figs. 60-63.

Basidioma anual, sésil a dimidiado, plano, gregario, de consistencia correosa a coriácea, de 25-200 X 20-80 X 5-10 mm. Píleo híspido, con pelos rígidos hasta de $5 \mathrm{~mm}$ de longitud, zonado, de color café obscuro a negro $(6 \mathrm{~F} 3,6 \mathrm{~F} 4)$, con algunas zonas de color púrpura-negro (8F1); margen agudo, ondulado y estéril. Himenóforo con poros de color café claro (5D4), de tamaño mediano, de 4-5 por mm, circulares, regulares, con bordes gruesos y lisos u ondulados; tubos de color café-gris claro (5D3), hasta de $2.5 \mathrm{~mm}$ de longitud, no estratificados. Contexto de color café claro (5D4), hasta de $2.5 \mathrm{~mm}$ de grosor, simple, fibroso. Sabor y olor no detectados. Sistema hifal trimítico; hifas generativas de 2-3.2 $\mu \mathrm{m}$ de diámetro, con fíbulas, hialinas, con paredes delgadas; hifas esqueléticas de 3.2-4.8 $\mu \mathrm{m}$ de diámetro, de color café claro a sepia, con paredes gruesas a muy gruesas (casi sólidas), rectas; hifas conectivas de 1.6-2.4 $\mu \mathrm{m}$ de diámetro, amarillentas, con paredes gruesas, sinuosas. Cistidios y otros elementos himeniales estériles ausentes. Basidios no observados. Basidiosporas de $9.6 \mathrm{X} 4 \mu \mathrm{m}$, elipsoides, hialinas, inamiloides, con pared delgada y lisa.

Reacciones macroquímicas: el píleo y el contexto viran a color café-negro; el himenóforo vira a color café o café-grisáceo.

Hábitat: Sobre madera muerta de angiospermas o parasitando individuos de Bursera sp., Ocasiona pudrición blanca.

Material estudiado: CHIAPAS: Medina 59, 79, 166; Valenzuela 4949, 4965 (CONABIO 1363, 1364, 1365, 1431, 1432).

Distribución conocida en México: Es común en vegetación secundaria, se conoce de Campeche, Chiapas, Colima, Distrito Federal, Durango, Estado de México, Guanajuato, Guerrero, Hidalgo, Jalisco, Michoacán, Morelos, Nayarit, Nuevo León, Oaxaca, Puebla, Querétaro, Quintana Roo, San Luis Potosí, Sierra Madre Oriental, Tabasco, Tamaulipas, Veracruz y Yucatán (Bandala et al., 1993; Valenzuela et al., 2002; Raymundo y Valenzuela, 2003; Cifuentes et al., 2004; Landeros et al., 2006). 
Hexagonia tenuis (Hook.) Fr., Epicr. Syst. Mycol. p. 498 (1838). Figs. 64-67.

Basidioma anual, pileado-sésil, semicircular, plano, gregario, de consistencia papirácea, de 30-160 X 25-85 X 1.5-2 mm. Píleo glabro, zonado a surcado, anaranjado-grisáceo a de color topacio (5B5, 5C5), puede presentar una cutícula negro-rojiza o rojiza; margen agudo, ondulado y fértil. Himenóforo con poros de color arena (4B3), grandes, $0.5-1.5$ poros por $\mathrm{mm}$, hexagonales, regulares, con bordes delgados $\mathrm{y}$ lisos; tubos del mismo color que los poros, hasta de $1 \mathrm{~mm}$ de longitud, no estratificados. Contexto amarillo brillante (4A4), hasta de $1 \mathrm{~mm}$ de grosor, simple, fibroso, con sabor ligeramente amargo y olor fúngico. Sistema hifal trimítico; hifas generativas de 1.6-3.2 $\mu \mathrm{m}$ de diámetro, con fíbulas, hialinas, con paredes delgadas; hifas esqueléticas de 3.2-5.6 $\mu \mathrm{m}$ de diámetro, hialinas a amarillentas, con paredes gruesas a casi sólidas, rectas a sinuosas; hifas conectivas de 2.4-3.2 $\mu \mathrm{m}$ de diámetro, hialinas, con paredes gruesas a sólidas, sinuosas. Cistidios y otros elementos himeniales estériles ausentes. Basidios no observados. Basidiosporas de 8-12 X 3.2-4.8 $\mu \mathrm{m}$, elipsoides a cilíndricas, hialinas, inamiloides, lisas, con paredes delgadas.

Reacciones macroquímicas: el píleo y el contexto cambian a color café oscuro o negro; el himenóforo cambia a color café.

Hábitat: Sobre madera muerta de angiospermas. Ocasiona pudrición blanca.

Material revisado: CHIAPAS: Medina 66, Valenzuela 4986 (CONABIO 3919, 5328).

Distribución conocida en México: Es típica de ambientes tropicales, se ha citado de Campeche, Chiapas, Chihuahua, Colima, Jalisco, Michoacán, Morelos, Oaxaca, Querétaro, Quintana Roo, San Luis Potosí, Sierra Madre Oriental, Sonora, Veracruz, Yucatán (Bandala et al., 1993; Pérez-Silva et al., 1993; Guzmán-Dávalos y Fragosa-Díaz, 1994; Chacón et al., 1995; Esqueda-Valle et al., 1999; Herrera-Fonseca y Guzmán-Dávalos, 2002; Valenzuela et al., 2002; Raymundo y Valenzuela, 2003; Cifuentes et al., 2004; Chanona-Gómez et al., 2007; Díaz-Moreno et al., 2009).

Lenzites elegans (Spreng.) Pat., Essai Tax. Hyménomyc. 89 (1900). Figs. 68-71.

Basidioma anual, sésil o con una base a manera de estípite, circular a ligeramente infundibuliforme, imbricado, de consistencia correosa, de 35-170 X 30-140 X 5-20 mm. Píleo glabro, surcado, blanco a blanco-amarillento pálido (2A1, 2A2), con tonos amarillo-melón (5A6); margen agudo, entero a ligeramente ondulado, estéril. Himenóforo con poros de color blanco amarillento a amarillo-maíz (2A2, 4A6), medianos a grandes, de 2-4 por mm, circulares a angulares, muy variables en forma, a 

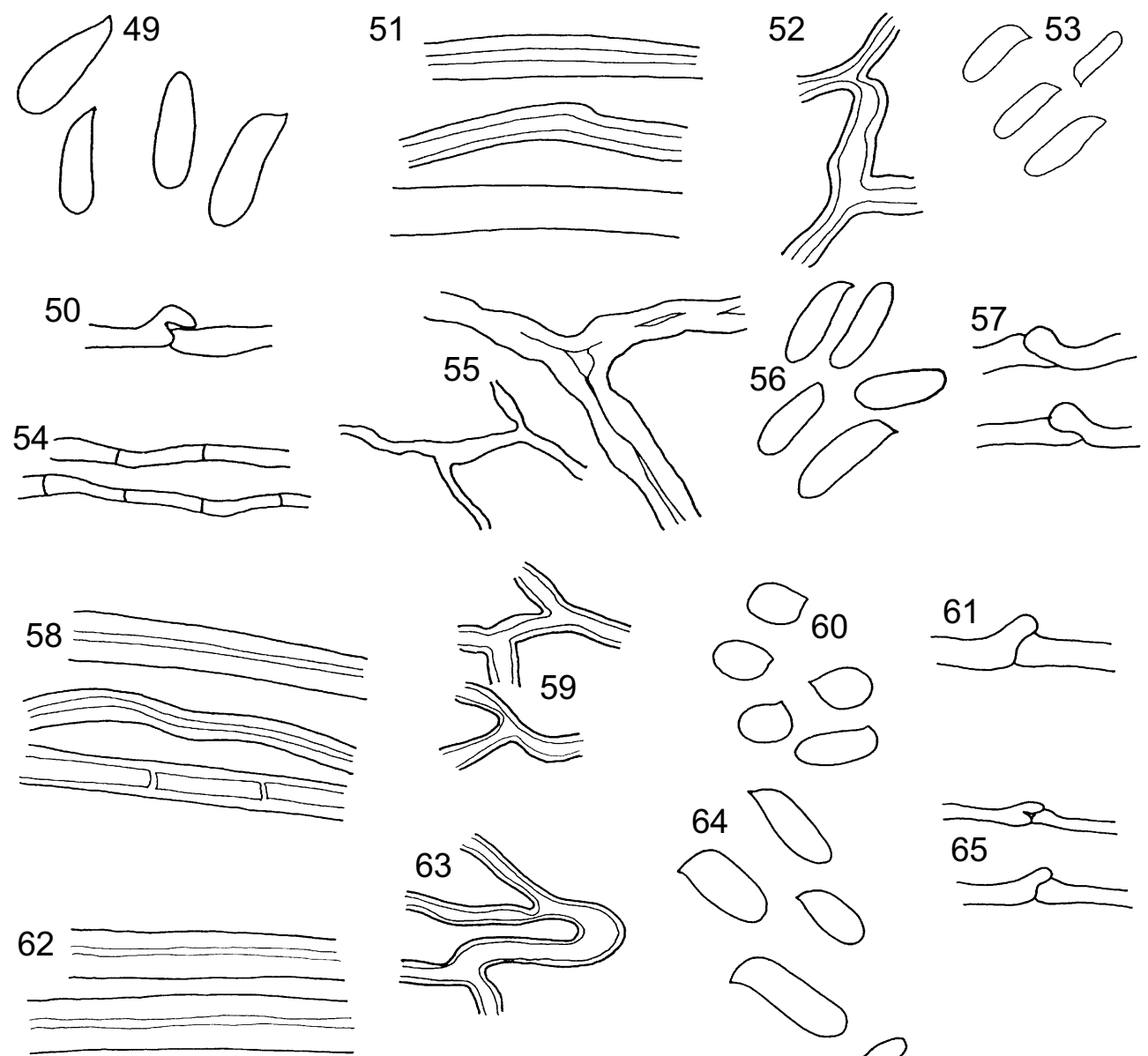

66
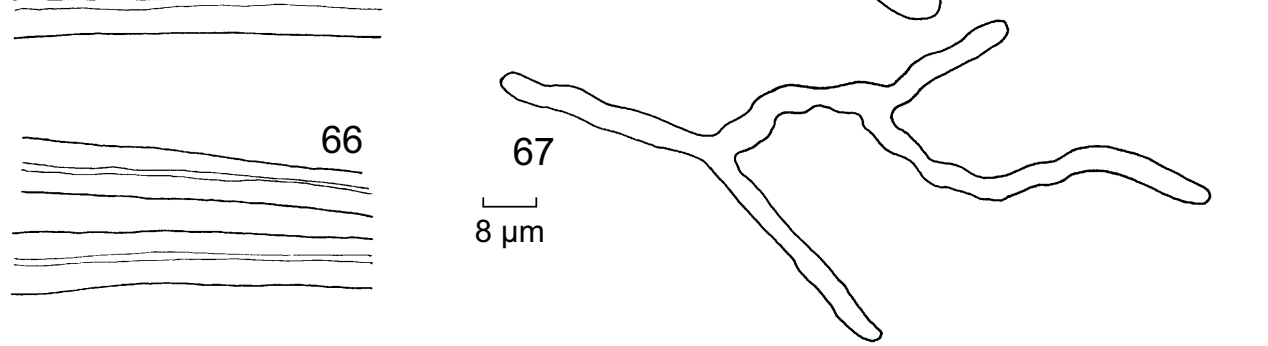

Figs. 49-67. Earliella scabrosa: 49. basidiosporas; 50. hifas generativas; 51. hifas esqueléticas; 52. hifas conectivas. Favolus tenuiculus: 53. basidiosporas; 54. hifas generativas; 55. hifas conectivas. Fomes fasciatus: 56 . basidiosporas; 57 . hifas generativas; 58 . hifas esqueléticas sin septos; 59. hifas conectivas. Hexagonia hydnoides: 60. basidiosporas; 61. hifas generativas; 62. hifas esqueléticas; 63. hifas conectivas. Hexagonia tenuis: 64. basisiosporas; 65. hifas generativas; 66 . hifas esqueléticas; 67 . hifas conectivas 
veces labirintiformes hacia la base con bordes delgados y ligeramente irpiciformes; tubos concoloros con los poros, hasta de $1 \mathrm{~mm}$ de longitud, no estratificados. Estípite, cuando existe, lateral o excéntrico, hasta de $30 \mathrm{X} 15 \mathrm{~mm}$, del mismo color y textura que el píleo, compacto. Contexto blanco (4A1), hasta de $2.5 \mathrm{~mm}$ de grosor, simple, fibroso. Sabor y olor no detectados. Sistema hifal trimítico; hifas generativas de 1.2-2.4 $\mu \mathrm{m}$ de diámetro, con fíbulas, hialinas, con paredes delgadas; hifas esqueléticas de 3.2-5.6 $\mu \mathrm{m}$ de diámetro, hialinas a amarillentas, con paredes gruesas a casi sólidas; hifas conectivas de 1.2-2.4 $\mu \mathrm{m}$ de diámetro, hialinas a amarillentas, con paredes gruesas a casi sólidas. Cistidios y otros elementos himeniales estériles ausentes. Basidios no observados. Basidiosporas de 4.8-7.2 X 2.4-3.2 $\mu \mathrm{m}$, elipsoides a cilíndricas, hialinas, inamiloides, con pared delgada, lisas.

Reacciones macroquímicas: cambia a amarillo y posteriormente a sepia en todas sus partes.

Hábitat: Sobre madera muerta de angiospermas. Ocasiona pudrición blanca.

Material revisado: CHIAPAS: Medina 13, 135; Valenzuela 4910 (CONABIO 1439).

Distribución conocida en México: Campeche, Chiapas, Chihuahua, Estado de México, Guerrero, Hidalgo, Jalisco, Michoacán, Morelos, Nuevo León, Oaxaca, Puebla, Quintana Roo, San Luis Potosí, Sierra Madre Oriental, Tabasco, Tamaulipas, Veracruz y Yucatán (Bandala et al., 1993; Guzmán-Dávalos y Fragosa-Díaz, 1994; Raymundo y Valenzuela, 2003; Cifuentes et al., 2004; Díaz-Moreno et al., 2009).

Loweporus tephroporus (Mont.) Ryvarden, Prelim. Polyp. F1. E. Afr. 416 (1980). Figs. 72-75.

Basidioma perenne, resupinado, solitario, de consistencia leñosa, de 40-50 X 60-120 X $5.8 \mathrm{~mm}$. Himenóforo con poros de color gris-café (6C3), de tamaño mediano, de 1-3 por $\mathrm{mm}$, circulares-irregulares (se modifican según la topografía del basidioma), con bordes gruesos y ondulados, margen fértil; tubos de color gris oscuro a gris-café (6C3), de 1-3 mm de longitud, inclinados respecto al plano del basidioma. Contexto del mismo color que los tubos, hasta de $0.5 \mathrm{~mm}$ de grosor, simple, fibroso; con sabor y olor ligeramente fúngico. Sistema hifal trimítico; hifas generativas de 2.4-3.2 $\mu \mathrm{m}$ de diámetro, con fíbulas, hialinas, con paredes delgadas; hifas esqueléticas de 3.2-5.6 $\mu \mathrm{m}$ de diámetro, amarillentas a oliváceas, con paredes gruesas a casi sólidas, rectas; hifas conectivas de 1-2 $\mu \mathrm{m}$ de diámetro, amarillentas a oliváceas, con paredes gruesas a casi sólidas, sinuosas. Cistidios y otros elementos 
himeniales estériles ausentes. Basidios no observados. Basidiosporas de 5.6-6.4 X 4-4.8 $\mu \mathrm{m}$, globosas o subglobosas, truncadas o no, amarillentas a oliváceas, variablemente dextrinoides (de color café-amarillento a café-rojizo), con pared gruesa, lisas.

Reacciones macroquímicas: cambia a negro en todas sus partes.

Hábitat: Sobre madera muerta de angiospermas, ocasionan pudrición blanca.

Material estudiado: CHIAPAS: Medina 42, Valenzuela 4933 (CONABIO 1373, 1441).

Distribución conocida en México: Oaxaca, Veracruz y Yucatán (Bandala et al., 1993).

Polyporus leprieurii Mont., Ann. Sci. Nat. Bot. 13(1): 208 (1840). Figs. 76-79.

Basidioma anual, pileado-estipitado, flabeliforme a infundibuliforme, disperso a gregario, de consistencia correosa. Píleo de 12-50 X 13-35 X 1-2 mm, glabro, liso, zonado y estriado, amarillo claro, anaranjado claro o de color cafésepia (4A4, 5A4); margen glabro, agudo, entero a ondulado y fértil. Himenóforo con poros de color crema a anaranjado-grisáceo (5B3, 4A3), muy pequeños, de 7-9 por $\mathrm{mm}$, angulares, irregulares, con bordes delgados y lisos; tubos de color anaranjado pálido a anaranjado-grisáceo (5A3, 5B4), hasta de $1 \mathrm{~mm}$ de longitud, no estratificados. Estípite de 7-40 X 1-3 mm, lateral o excéntrico, glabro a finamente pubescente, negro, de consistencia leñosa. Contexto de color café claro, hasta de $0.5 \mathrm{~mm}$ de grosor, simple, fibroso; con sabor ligeramente amargo, olor no detectado. Sistema hifal dimítico; hifas generativas de 2.4-3.2 $\mu \mathrm{m}$ de diámetro, con fíbulas, hialinas a amarillentas, con pocas o muchas ramificaciones; hifas conectivas de 2.6-4 $\mu \mathrm{m}$ de diámetro, hialinas a amarillentas, con paredes gruesas a sólidas, onduladas, sinuosas, con pocas o muchas ramificaciones. Cistidios y otros elementos himeniales estériles ausentes. Basidios de 16-20 X 4.8-6.4 $\mu \mathrm{m}$, hialinos, con paredes delgadas, lisos, tetrasporados, claviformes. Basidiosporas elipsoides, ampliamente elipsoides o cilíndricas, de 4.8-8 X 1.6-4 $\mu \mathrm{m}$, hialinas, inamiloides, lisas, con pared delgada.

Reacciones macroquímicas: en $\mathrm{KOH}$ a $5 \%$ el píleo y el contexto cambian a negro, y se aclaran posteriormente; el himenóforo se torna gris claro y el estípite permanece sin cambios.

Hábitat: Sobre madera muerta de angiospermas. Ocasiona pudrición blanca.

Material estudiado: CHIAPAS: Butrón s. n. (diciembre 1985), Medina 118, Valenzuela 5053 (CONABIO 1375, 1443). 
Distribución conocida en México: Chiapas, Estado de México, Hidalgo, Michoacán, Quintana Roo, Sierra Madre Oriental, Tamaulipas, Veracruz (Bandala et al., 1993; Cifuentes et al., 2004).

Polyporus tricholoma Mont., Ann. Sci. Nat., Bot., sér. 2, 8: 365 (1837). Figs. 80-82.

Basidioma anual, pileado, estipitado, umbilicado, solitario a gregario, de consistencia correosa. Píleo de 7-20 X 7-20 X 0.5-1 mm, glabro, liso a ligeramente rugoso, amarillo brillante a de color café-dorado (4A4, 5D7); margen de color sepia, agudo, crenado y fértil, con pelos en el borde hasta de $2 \mathrm{~mm}$ de longitud. Himenóforo con poros amarillos brillantes (4A4), pequeños, angulares, regulares, de bordes delgados y crenados, 4-6 por $\mathrm{mm}$; tubos del mismo color del himenio, hasta de $0.5 \mathrm{~mm}$ de longitud, no estratificados. Contexto amarillo brillante (4A4), hasta de $0.8 \mathrm{~mm}$ de grosor, fibroso, simple; con sabor y olor fuertemente fúngico. Sistema hifal dimítico; hifas generativas de 2.4-4 $\mu \mathrm{m}$ de diámetro, con fíbulas, hialinas, con paredes delgadas; hifas conectivas de 2.4-3.6 $\mu \mathrm{m}$ de diámetro, hialinas, con paredes gruesas a casi sólidas, sinuosas, ramificadas. Cistidios y otros elementos himeniales estériles ausentes. Basidios de $20 \mathrm{X} 4 \mu \mathrm{m}$, claviformes, hialinos, con pared delgada, lisos, bisporados. Basidiosporas de 6.4-8 X 2.8-3.6 $\mu \mathrm{m}$, cilíndricas, hialinas, inamiloides, lisas, con pared delgada.

Reacciones macroquímicas: no vira en ninguna de sus partes.

Hábitat: Sobre madera muerta de angiospermas. Ocasiona pudrición blanca.

Material revisado: CHIAPAS: Medina 36; Valenzuela 4929 y 5024 (CONABIO 1377, 1445, 1446).

Distribución conocida en México: Es cosmopolita, se distribuye en Campeche, Chiapas, Chihuahua, Colima, Durango, Estado de México, Guerrero, Jalisco, Michoacán, Morelos, Nuevo León, Oaxaca, Puebla, Querétaro, Quintana Roo, Sierra Madre Oriental, Sonora, Tabasco, Tamaulipas, Veracruz y Yucatán (Bandala et al., 1993; Pérez-Silva et al., 1993; Esqueda-Valle et al., 1999; Herrera-Fonseca y Guzmán-Dávalos, 2002; Valenzuela et al., 2002; Raymundo y Valenzuela, 2003; Cifuentes et al., 2004; Díaz-Moreno et al., 2009).

Polyporus varius (Pers.) Fr., Syst. Mycol. (Lundae) 1: 352 (1821). Figs. 84-86.

Basidioma anual, pileado-estipitado, flabeliforme, de consistencia correosa. Píleo de 12-60 X 17-40 X 3-5 mm, glabro, liso, blanco, amarillento de color arena (2A2, 4B3), con manchas laqueadas de color castaño oscuro a negro-púrpura (6F7, $6 \mathrm{~F} 3$ ), irregulares en forma y tamaño; margen entero, obtuso y fértil. Himenóforo 

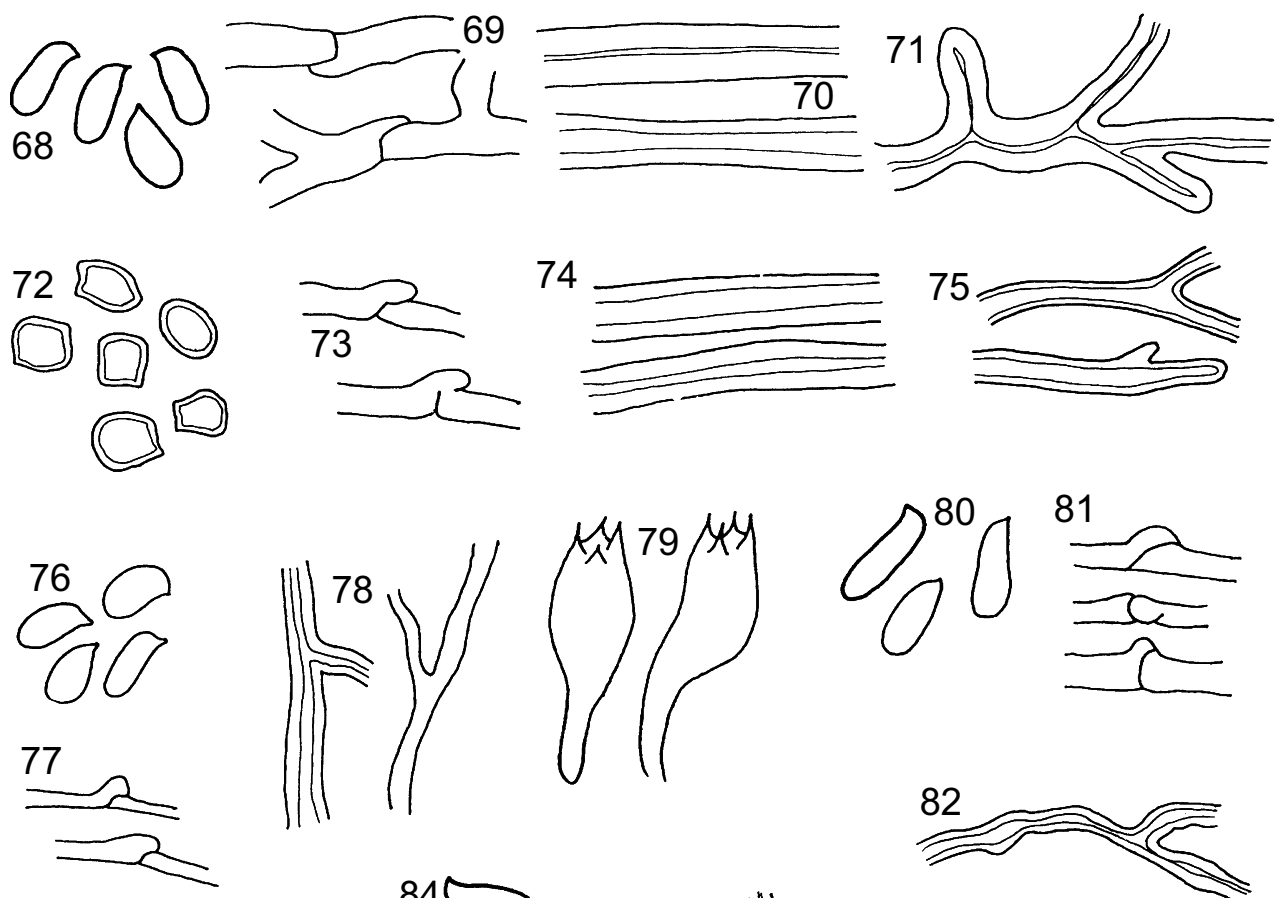

83
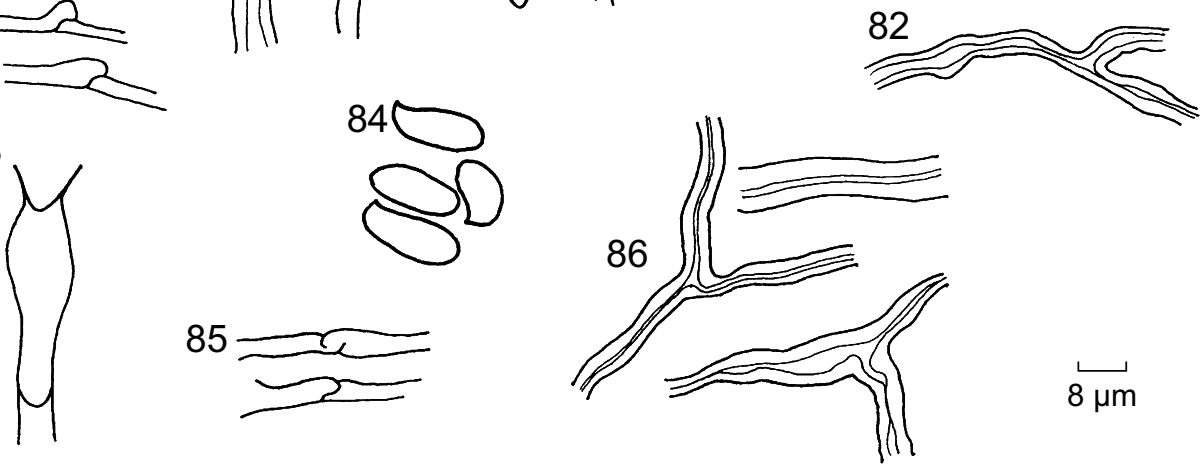

Figs. 68-86. Lenzites elegans: 68 . basidiosporas; 69. hifas generativas; 70. hifas esqueléticas; 71. hifas conectivas. Loweporus thephroporus: 72. basidiosporas; 73. hifas generativas; 74 . hifas generativas; 75 . hifas conectivas. Polyporus leprieurii: 76. basidiosporas; 77. hifas generativas; 78. hifas conectivas; 79. basidios. Polyporus tricholoma: 80 . basidiosporas; 81 . hifas generativas; 82 . hifas conectivas; 83 . basidio. Polyporus varius: 84 . basidiosporas; 85 . hifas enerativas; 86. hifas conectivas.

con poros blanco-amarillentos a de color arena (2A2, 4B3), pequeños, 5-7 por mm, circulares, con bordes delgados y lisos; tubos del mismo color, de 1.5-3 mm de longitud, no estratificados. Estípite de 10-40 X 3-6 mm, lateral, glabro, liso a ligeramente rugoso, del color de las manchas del píleo, de sección circular a elipsoide, engrosado 
hacia la base, sólido. Contexto del mismo color que el himenóforo, de 1-3 $\mathrm{mm}$, de grosor, fibroso algodonoso, simple. Sistema hifal dimítico; hifas generativas de 2.8$3.2 \mu \mathrm{m}$ de diámetro, con fíbulas, hialinas, con paredes delgadas; hifas conectivas de 1.6-8 $\mu \mathrm{m}$ de diámetro, hialinas, con paredes gruesas a casi sólidas, rectas a sinuosas, poco o muy ramificadas (tipo dendroide). Cistidios y otros elementos himeniales estériles ausentes. Clavijas hifales no observadas. Basidios no observados. Basidiosporas de 6.4-10.4 X 2.4-3.2(-4) $\mu \mathrm{m}$, elipsoides a cilíndricas, hialinas, inamiloides, con pared delgada, lisas, con gotas refringentes en el citoplasma.

Reacciones macroquímicas: el estípite y las manchas del píleo cambian a color caoba muy oscuro o a negro; el píleo y el himenóforo viran a color café oscuro; el contexto cambia a color sepia y posteriormente se aclara.

Hábitat: Sobre madera muerta de angiospermas. Ocasiona pudrición blanca.

Material revisado: CHIAPAS: Butrón s. n. (diciembre 1985).

Distribución conocida en México: Chiapas, Chihuahua, Durango; Estado de México, Jalisco; Michoacán, Quintana Roo, Tamaulipas, Veracruz y Yucatán (Bandala et al., 1993; Ryvarden y Guzmán, 1993; Guzmán-Dávalos y Fragosa-Díaz, 1994; Herrera-Fonseca y Guzmán-Dávalos, 2002; Díaz-Moreno et al., 2005; Chanona-Gómez et al., 2007; Díaz-Moreno et al., 2009).

Trametes maxima (Mont.) A. David \& Rajch., Mycotaxon 22(2): 315 (1985). Figs. 87-90.

Basidioma anual, pileado-sésil a efuso-reflejo, semicircular, plano, solitario a ligeramente imbricado, de consistencia correosa, de 35-150 X 30-120 X 3-8 mm. Píleo villoso, zonado y sulcado, amarillo brillante a amarillo-mantequilla (4A4, 4A5), llega a tener tonalidades verdosas por la presencia de algas; margen ondulado, agudo y estéril. Himenóforo con poros de color amarillo-albaricoque a amarillo-dorado, o de color crema a amarillo brillante (5B6, 5B7, 4A3, 4A4), de tamaño mediano, 1-3 por $\mathrm{mm}$, angulares e irregulares, con bordes delgados y dentados; tubos concoloros al himenóforo, de 0.5.2 mm de longitud, no estratificados. Contexto blanco, de 0.5-2 mm de grosor, dúplex, con una capa bajo el píleo de hasta $0.2 \mathrm{~mm}$ de grosor, anaranjadoblanquecina a rojizo-dorada (5A2, 6C7), de aspecto ceroso en ejemplares secos; sabor y olor fúngico. Sistema hifal trimítico; hifas generativas de 1.6-2.8 $\mu \mathrm{m}$ de diámetro, con fíbulas, hialinas, con paredes delgadas; hifas esqueléticas de 4-4.8 $\mu \mathrm{m}$ de diámetro, hialinas, con paredes gruesas a casi sólidas; hifas conectivas de 1.2-3.2 $\mu \mathrm{m}$ de diámetro, hialinas, con paredes gruesas a sólidas, sinuosas. Clavijas hifales abundantes y conspicuas al microscopio estereoscópico (20X). Cistidios ausentes. Basidios no 

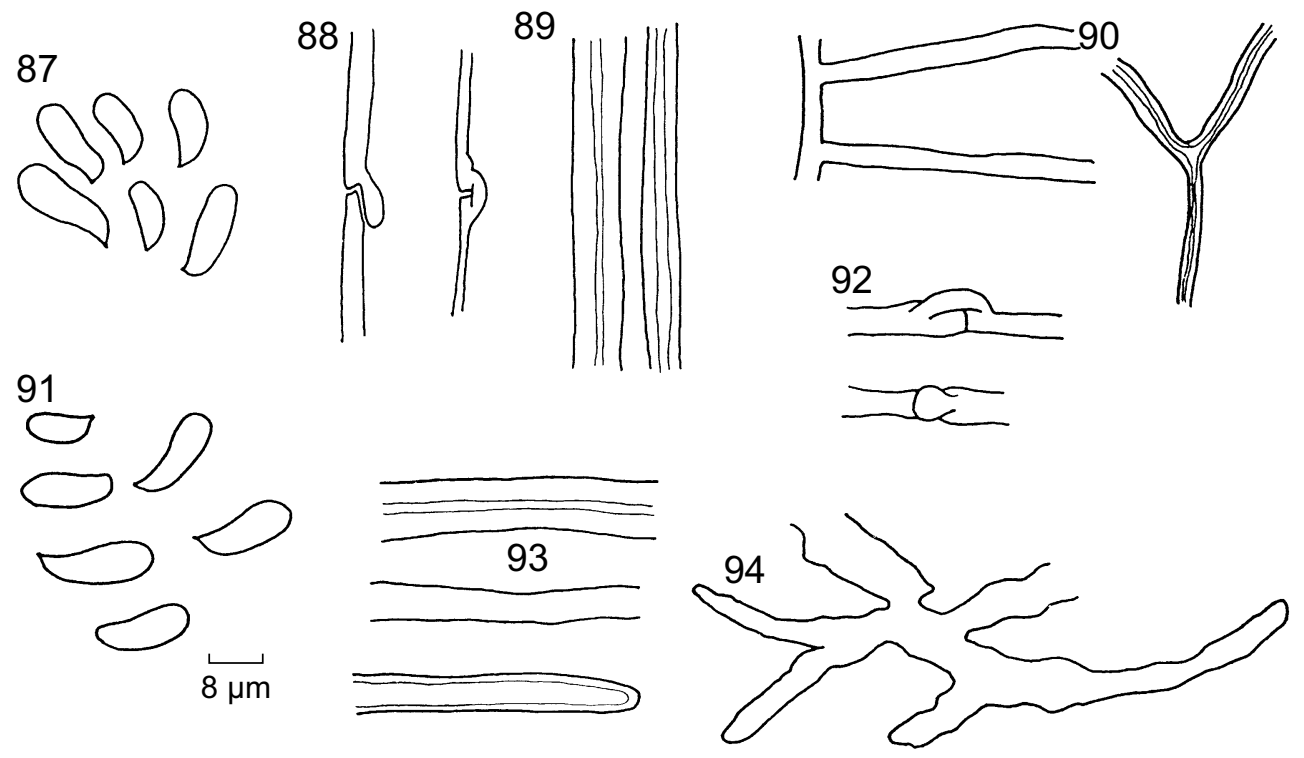

Figs. 87-94. Trametes maxima: 87 . basidiosporas; 88. hifas generativas; 89 . hifas esqueléticas; 90. hifas conectivas. Trametes villosa: 91. basidiosporas; 92. hifas generativas; 93. hifas esqueléticas; 94. hifas conectivas.

observados. Basidiosporas de 4.8-5.6 X 2.4-3.2 $\mu \mathrm{m}$, cilíndricas, hialinas, inamiloides, con pared delgada, lisas, citoplasma de aspecto homogéneo a heterogéneo.

Reacciones macroquímicas: en $\mathrm{KOH}$ a 5\% es negativa en todas sus partes.

Hábitat: Sobre madera muerta de angiospermas. También se encontró parasitando a Citrus maxima (Burm.) Merr. cultivada junto al bosque. Ocasiona pudrición blanca.

Material revisado: CHIAPAS: Medina 19, 87, (CONABIO 3723, 3724); Valenzuela 4916 (marzo 30 1986) y 4975 (abril 1 1986).

Distribución conocida en México: Campeche, Chiapas, Hidalgo, Jalisco, Nuevo León, Oaxaca, Puebla, Querétaro, Quintana Roo, San Luis Potosí, Sierra Madre Oriental, Sonora, Tamaulipas, Veracruz y Yucatán (Bandala et al., 1993; Chacón y Guzmán, 1994; Guzmán-Dávalos y Fragosa-Díaz, 1994; Rodríguez et al., 1994; Esqueda-Valle et al., 1999; Valenzuela et al., 2002; Raymundo y Valenzuela, 2003; Cifuentes et al., 2004).

Trametes villosa (Sw.) Kreisel, Monografias, Ciencias, Univ. Habana, Ser. 4 16: 83 (1971). Figs. 91-94. 
Basidioma anual, efuso-reflejo a sésil, semicircular o dimidiado, plano, de consistencia correosa a corchosa, de 10-60 X 8-48 X 1-2 mm. Píleo tomentoso, viloso o estrigoso, zonado, con estrías radiales, de color blanco con amarillo-vino (1A1, 3B3), a veces con tonalidades verdes debidas al crecimiento de algas; margen agudo, ondulado y estéril. Himenóforo con poros de color café-amarillento a café-ciervo (5E8, 5F8, 7F4), medianos, 1.5-3 por mm, hexagonales, regulares o irregulares, con bordes delgados y dentados; tubos del mismo color que los poros, hasta de $0.5 \mathrm{~mm}$ de longitud, no estratificados. Contexto blanco (1A1), hasta de $0.5 \mathrm{~mm}$ de grosor, de aspecto farinoso, dúplex, con una capa delgada de color café claro a muy oscuro bajo el tomento; sabor y olor fúngico. Sistema hifal trimítico; hifas generativas de 2.4-3.2 $\mu \mathrm{m}$ de diámetro, con fíbulas, hialinas, con paredes delgadas; hifas esqueléticas de 3.2-6.4 $\mu \mathrm{m}$ de diámetro, hialinas, con paredes gruesas a sólidas, sinuosas; hifas conectivas de 2.4-4 $\mu \mathrm{m}$ de diámetro, hialinas, de paredes gruesas a sólidas. Clavijas hifales desde $100 \times 12 \mu \mathrm{m}$, recubiertas de himenio; se pueden observar con un aumento de 16X. Basidios no observados. Basidiosporas de 4.8-7.2 X $3.2 \mu \mathrm{m}$, elipsoides a cilíndricas, hialinas, inamiloides, con pared delgada, lisas.

Reacciones macroquímicas: el píleo y el contexto cambian a colores sepia y café-gris claro, respectivamente; el himenóforo adquiere tonos amarillos.

Hábitat: Sobre madera muerta de angiospermas. Ocasiona pudrición blanca.

Material revisado: CHIAPAS: Butrón s. n. (diciembre 1985), Medina 15, 123 (CONABIO 1390, 1391); Valenzuela 4912, 5007.

Distribución conocida en México: Baja California, Campeche, Chiapas, Chihuahua, Colima, Distrito Federal, Estado de México, Guanajuato, Hidalgo, Jalisco, Michoacán, Morelos, Nuevo León, Oaxaca, Puebla, Querétaro, Quintana Roo, San Luis Potosí, Sierra Madre Oriental, Sonora, Tabasco, Tamaulipas, Veracruz y Yucatán (Bandala et al., 1993; Pérez-Silva et al., 1993; Guzmán-Dávalos y Fragosa-Díaz, 1994; Esqueda-Valle et al., 1999; Herrera-Fonseca y Guzmán-Dávalos, 2002; Valenzuela et al., 2002; Raymundo y Valenzuela, 2003; Cifuentes et al., 2004; Montaño et al., 2006; Díaz-Moreno et al., 2009).

\section{CONCLUSIONES}

Yaxchilán es una zona importante debido a que en ella existen ruinas mayas y a que es una de las pocas regiones de la Selva Lacandona que ha sido menos perturbada. En este tipo de comunidad existe poca oscilación térmica y las precipitaciones pluviales se encuentran esparcidas regularmente a lo largo de todo el año, por lo que 
la época de reproducción de los organismos que ahí habitan no está determinada por cambios estacionales y varía de una especie a otra. Tomando en cuenta todo esto, el hecho de hallar 27 poliporoides diferentes en una sola exploración sugiere que la diversidad de los mismos puede ser muy grande. En el caso de Gloeoporus thelephoroides (Hook.) G. Cunn. es esta la primera descripción basada en ejemplares mexicanos.

\section{AGRADECIMIENTOS}

Para este trabajo se contó con el apoyo del proyecto SIP 20121207. Medina y Valenzuela agradecen el apoyo de COFAA.

\section{LITERATURA CITADA}

Anónimo. 1981. Atlas nacional del medio físico. Dirección General de Geografía del Territorio Nacional. Secretaría de Programación y Presupuesto. México, D.F., México. 224 pp.

Bandala, V. M., G. Guzmán y L. Montoya. 1993. Los hongos del grupo de los poliporáceos conocidos en México. Revista Forestal (núm. esp. UANL) 13: 1-55.

Bondartsev, A. S. 1971. The Polyporaceae of the European USSR and Caucasia. U.S. Dept. Commerce, National Technical Information Service. Springfield, USA. 896 pp.

Breedlove, D. E. 1981. Flora of Chiapas, I. California Academy of Sciences. San Francisco, USA. 35 pp.

Chacón, S. y G. Guzmán. 1984. Nuevas observaciones sobre los hongos, líquenes y mixomicetos de Chiapas. Bol. Soc. Mex. Mic. 19: 245-251.

Chacón, S., G. Guzmán, L. Montoya y V. M. Bandala. 1995. Guía ilustrada de los hongos del Jardín Botánico Francisco J. Clavijero de Xalapa, Veracruz y áreas circunvecinas. Instituto de Ecología, A.C. Xalapa, México. 142 pp.

Chacón, S. y G. Guzmán. 1995. Observations on the phenology of ten fungal species in the subtropical forests at Xalapa, Mexico. Mycol. Res. 99: 54-56.

Chanona-Gómez, F., R. H. Andrade-Gallegos, J. Castellanos-Albores y J. E. Sánchez. 2007. Macromicetos del Parque Educativo Laguna Bélgica, municipio de Ocozocoautla de Espinosa, Chiapas, México. Rev. Mex. Biodiv. 78(2): 369-381.

Cifuentes, J., M. Villegas y L. Pérez-Ramírez. 1986. Hongos. In: Lot, A. y F. Chiang, Compiladores. Manual de herbario. Consejo Nacional de la Flora de México, A.C., México, D.F., México. pp. 55-64.

Cifuentes-Blanco, J., M. Villegas-Ríos, R. García-Sandoval, G. Vidal-Gaona, S. SierraGalván, R. Valenzuela-Garza, L. Pérez-Ramírez y E. Morales-Torres. 2004. Distribución de macromicetos: una aproximación al análisis de áreas de endemismo. In: Luna, I., J. J. Morrone y D. Espinosa (eds.). Biodiversidad de la Sierra Madre 
Oriental. Comisión Nacional para el Estudio de la Biodiversidad. México, D.F., México. pp. 355-374.

Cooke, R. C. y A. D. M. Rayner. 1984. Ecology of saprotrofic fungi. Longman Inc. Nueva York, USA. 415 pp.

Cullen, D. y P. J. Kersten. 1996. Enzimology and molecular biology of lignin degradation In: Brambl, R. y G. A. Marzuf (eds.). The Mycota: biochemistry and molecular biology. Vol. III. Springer-Verlag. Berlin, Alemania. pp. 249-273.

Díaz-Moreno, R., J. G. Marmolejo y R. Valenzuela. 2005. Flora micológica de bosques de pino y pino-encino en Durango, México. Ciencia (UANL) 8: 362-369.

Díaz Moreno, R., R. Valenzuela, J. G. Marmolejo y E. Aguirre-Acosta. 2009. Hongos degradadores de la madera en el estado de Chihuahua, México. Rev. Mex. Biodiv. 80(1): 13-22.

Domanski, S. 1972. Fungi II, Polyporaceae I (resupinate) and Mucronoporaceae I (resupinate). U.S. Dept. Agr. Nat. Sci. Found. Washington, DC., USA. 234 pp.

Domanski, S., H. Ortos y A. Skirgiello. 1973. Fungi III, Polyporaceae II (pileatae), Mucronoporaceae II (pileatae), Ganodermataceae, Bondarzewiaceae, Boleptosidaceae and Fistulinaceae. U.S. Dept. Agr. Nat. Sci. Found., Washington, DC, USA. 243 pp.

Esqueda-Valle, M., E. Pérez-Silva, F. San Martín y R. Santos. 1999. Macromicetos de selva baja caducifolia I: Álamos, Sonora, México. Rev. Mex. Mic. 15: 73-78.

Gilbertson, R. L. 1976. The genus Inonotus (Aphyllophorales: Hymenochaetaceae) in Arizona. Mem. New York Bot. Gard. 28: 67-85.

Gilbertson, R. L. y L. Ryvarden. 1986. North American polypores, I. AbortiporusLindtneria. Fungiflora, Oslo, Noruega. 433 pp.

Gilbertson, R. L. y L. Ryvarden. 1987. North American Polypores, II. MegasporoporiaWrightoporia. Fungiflora, Oslo, Noruega. pp. 434-885.

Guzmán, G. 1963. Frecuencia y distribución de algunos basidiomicetos lignícolas importantes en México. An. Esc. Nac. Cienc. Biol. 12: 23-41.

Guzmán, G. 1972. Macromicetos mexicanos en el herbario The National Fungus Collections, de E.U.A. Bol. Soc. Bot. Mex. 32: 31-55.

Guzmán, G. 1977. Identificación de los hongos comestibles, venenosos, alucinantes y destructores de la madera. Limusa. México, D.F., México. 236 pp.

Guzmán, G. y T. Herrera. 1972. Especies de macromicetos citadas de México, II: Fistulinaceae, Meruliaceae y Polyporaceae. Bol. Soc. Mex. Mic. 5: 57-77.

Guzmán, G. y P. D. Johnson. 1974. Registros y especies nuevas de los hongos de Palenque, Chiapas. Bol. Soc. Mex. Mic. 6: 17-53.

Guzmán Dávalos, L y G. Fragoza-Díaz. 1994. Los hongos registrados del estado de Jalisco. Bol. Ibug 2: 109-160.

Herrera Fonseca, M. J., L. Guzmán-Dávalos y O. Rodríguez. 2002. Contribución al conicimiento de la micobiota de la región de San Sebastián del Oeste, Jalisco, México. Acta Bot. Mex. 58: 19-50.

Kornerup, A. y J. H. Wanscher. 1978. Methuen handbook of colour. 3a. ed. Eyne Methuen. Londres, UK. 252 pp.

Landeros, F., J. Castillo, G. Guzmán y J. Cifuentes. 2006. Los hongos (macromicetos) conocidos en el Cerro el Zamorano (Querétaro-Guanajuato), México. Rev. Mex. Mic. 22: 25-31. 
Montaño, A., R. Valenzuela, A. Sánchez, M. Coronado y M. Esqueda. 2006. Aphyllophorales de Sonora, México, I. Algunas especies de la Reserva Forestal Nacional y Refuguio de la Fauna Silvestre de Ajos-Bavispe. Rev. Mex. Mic. 23: 17-26.

Nava, R. y R. Valenzuela. 1993. Los poliporáceos de México IV. Especies poco conocidas. Reporte Científico (Núm. esp.) 13: 182-193.

Overholts, L. O. 1953. The Polyporaceae of the United States, Alaska and Canada. The University of Michigan Press. Ann Arbor, USA. 466 pp.

Pérez-Moreno, J. y L. Villarreal. 1988. Los hongos y mixomicetos del estado de Chiapas, México. Estado actual, conocimiento y nuevos registros. Micología Neotropical 1: 97-133.

Raymundo, T. y V. Valenzuela. 2003. Los poliporáceos de México VI. Los hongos poliporoides del estado de Oaxaca. Polibotánica 16: 79-112.

Rodríguez, O., M. Garza y L. Guzmán-Dávalos. 1994. Inventario preliminar de los hongos del Volcán de Tequila, estado de Jalisco, México. Rev. Mex. Mic. 10: 103-111.

Ryvarden, L. 1991. Genera of polypores, nomenclature and taxonomy. Synopsis Fungorum 5. Fungiflora, Oslo, Noruega. 363 pp.

Ryvarden, L. y G. Guzmán. 1992. New records of polypores from Mexico. Mycotaxon 47: $1-23$.

Ryvarden, L. y I. Johansen. 1980. A preliminary polypore flora of East-Africa. Fungiflora, Oslo, Noruega. 636 pp.

Ryvarden, L. y R. L. Gilbertson. 1993. European polypores. Part I. Fungiflora, Oslo, Noruega. 387 pp.

Rzedowski, J. 1978. Vegetación de México. Limusa. México, D.F., México. 432 pp.

Valenzuela, R., C. de la Huerta, R. Fernández. 2002. Los poliporáceos de México V. Algunas especies del norte del estado de Querétaro. Polibotánica 14: 85-113.

Valenzuela, R., M. R. Palacios-Pacheco, T. Raymundo, S. Bautista-Hernández. 2006. Especies de poliporáceos poco conocidas en México. Rev. Mex. Biodiv. 77: 35- 49. 